\title{
Los NOOC para la formación en competencias digitales del docente universitario. Una experiencia piloto de la Universidad Nacional de Educación a distancia (UNED).
}

\author{
NOOCs for the development of university teachers' digital \\ competences. A pilot experience by the UNED (Universidad \\ Nacional de Educación a Distancia)
}

\author{
Lourdes Pérez Sánchez \\ Universidad Pontificia de Salamanca (España) \\ Iperezsa@upsa.es \\ María Jordano de la Torre \\ Universidad Nacional de Educación a Distancia (España) \\ mjordano@flog.uned.es \\ Ana María Martín-Cuadrado \\ Universidad Nacional de Educación a Distancia (España) \\ amartin@edu.uned.es
}

\begin{abstract}
Resumen
Este artículo describe la puesta en marcha de nueve cursos en formato NOOC (Nano Curso Masivo en Abierto) destinados a mejorar la formación del profesorado universitario en lo que se refiere a las competencias digitales dentro del área de la información, atendiendo a los tres elementos o sub-áreas que la forman: navegación, evaluación y almacenamiento, y a tres niveles de desempeño (básico, medio y avanzado). La referencia principal ha sido el documento Marco para el Desarrollo y el Conocimiento de la Competencia Digital en Europa (DigComp 2.0) elaborado por centro de investigación de la Comisión Europea (Ferrari, 2013).

Este estudio muestra los datos preliminares de esta primera edición que pretende servir de retroalimentación al resto de cursos posteriores que pudieran surgir, con el fin de mejorar lo ya existente.
\end{abstract}

Palabras clave: competencias digitales, formación docente, docente universitario, NOOC, formación virtual.

\begin{abstract}
:
This article describes the launch of the first edition of nine NOOC (Nano Open Online Courses) aimed to improve the digital competence of university teachers in terms of Information literacy, considering three main elements or sub-areas: searching, evaluation and information retrieval, according three levels of proficiency: elementary, intermediate and advanced. The primary reference to built these courses has been the document "DigComp 2.0: A Framework for Developing and Understanding Digital Competence in Europe" (Ferrari, 2013).

This study shows the preliminary results of the first edition of these NOOC have dropped a great source of valuable feedback to sharpen future versions of the same courses.
\end{abstract}

Keywords: Digital competences, teacher training, university teaching, NOOC, online training. 


\section{Introducción}

Desde el año 2007, la Comisión Sectorial de Tecnologías de la Información y las Comunicaciones de las Universidades Españolas (CRUE-TIC) viene realizando diversos estudios relacionados con el estado de la tecnología en el ámbito universitario. En la última obra publicada (Gómez Ortega, 2016) aparece, como primera conclusión general, el hecho de que "la mayoría de los usos educativos de la Web 2.0 se hacen sobre una base ad-hoc, por el profesorado motivado, el personal y los estudiantes afectados. Y estas experiencias, la mayor parte de los casos, no son escalables". Esta situación, no solo se está produciendo a nivel de la web 2.0, sino de las competencias digitales básicas por parte de profesorado, a nivel general. Ya que, si está lo suficientemente formado, será capaz de integrarlo en la preparación de la docencia que imparte. Esta afirmación no se refiere a la cantidad de contenidos que tenga disponibles en la web de la forma más atractiva posible, sino que se transfiere a otros muchos aspectos de su formación digital como, por ejemplo, la capacidad de gestionar la información. Dado que esta información está cada vez más ligada a las TIC (Tecnologías de la Información y de la Comunicación), si el docente no está mínimamente formado en este aspecto, difícilmente va a ser capaz de enseñar al alumno el camino óptimo para llegar a la información. Supuestamente, se recuerda como anécdota histórica cuando el profesor dictaba los apuntes en clase a partir de los que había sido capaz de recolectar de otras fuentes. Ahora, es el alumno el que debe ser capaz de llegar a sus fuentes primarias mediante la tecnología, y así llegar a recopilar un listado de fuentes bibliográficas que le ayuden a escribir sus trabajos de la mejor forma posible.

Si hasta hace unos años, las bases de datos y revistas en formato electrónico eran tan solo una de las versiones disponibles de las publicaciones más prestigiosas del mundo académico, hoy en día, se comienzan a publicar únicamente en versión digital. Gracias a esto y a otros factores derivados de la necesidad de difundir cada investigación llevada a cabo, la producción científica se está multiplicando de manera exponencial. Por ello, una vez localizada la información entre esa gran jungla de saber, es necesario tener capacidad suficiente para juzgarla de acuerdo con unos criterios de evaluación claros (Radom y Gammons, 2014) y que estén acorde con el nivel de conocimiento requerido en cada momento. Una vez consolidado este paso, es necesario saber de qué forma guardar la información encontrada de forma ordenada dependiendo de su tipología de forma que pueda ser localizada fácilmente en un futuro (Schoonbaert y Rosenberg, 2010), ya sea próximo o más alejado en el tiempo.

Documentos como DigComp (Carretero, Vuorikari y Punie, 2017) y sus diferentes versiones elaboradas específicamente para la ciudadanía, organizaciones y la educación (Redecker, 2017), publicados por la Unión Europea en los últimos años, se están encargando de recoger y unificar criterios a la hora de certificar el nivel competencial del usuario, al igual que ya se hizo en el área aprendizaje de lenguas extranjeras (Council of Europe, 2001).

Si bien se han dado ya ciertos pasos en el caso de la ciudadanía a nivel general, y a nivel docente preuniversitario (INTEF, 2017), está experiencia pretende abrir camino

Los NOOC para la formación en competencias digitales del docente universitario. Una experiencia piloto en una Universidad Nacional de Educación a Distancia (UNED). Lourdes Pérez-Sánchez, María Jordano de la Torre y Ana María Martín-Cuadrado.

Página 2 de 35 
en el terrero del profesorado universitario, cada vez más cercano a la enseñanza y aprendizaje digital.

Por todo lo comentado anteriormente, se ha optado por escoger el formato NOOC o nano curso masivo como el mejor medio de aprendizaje destinado a que un alumnado falto de tiempo pueda ponerse al día rápidamente en las diferentes necesidades de formación relacionadas con las TIC que le vayan surgiendo en cada momento de su carrera académica. Este tipo de aprendizaje flexible y catalogado como informal hasta hace unos años, se ha implantado en la universidad española en sus diferentes formatos, y está siendo ya analizado en términos de calidad y sostenibilidad para elaborar conclusiones que reviertan en el buen hacer de estos (Gea, 2016). Para corroborar esto, otros informes relacionados con la formación universitaria internacional, como el Horizon Report (2017), comienzan a encontrar ciertos inconvenientes en los LMS (Learning Management System), ya que son limitados en capacidad y demasiado centrados en el seguimiento administrativo del alumno más que en su propio aprendizaje (Conde et al., 2014).

\section{La competencia digital para el profesional docente e investigador universitario del s XXI}

Hasta hace unas décadas, una de las principales preocupaciones relativas a la formación docente, era la necesidad de cambio en el desempeño de los profesionales de la educación, llegando a cuestionar incluso la eficacia de la enseñanza tradicional, frente al uso de aquellas nuevas tecnologías de las que se comenzaba a hablar. Esas metodologías, que antes se consideraban "innovadoras", se están transformando en algo natural y usual de la era de la información en la que nos movemos. Este escenario ha provocado un elevado interés por mejorar las competencias digitales, a la vez que acrecienta la brecha digital de los que no llegan a ser mínimamente competentes en esta área. Esta situación no solo atañe a la vertiente puramente docente sino al campo de la investigación y de la gestión, ya que actualmente es completamente imposible acceder a la información únicamente mediante medios impresos, o realizar trámites administrativos por medios convencionales. Pozo (2010), en su modelo sobre la competencia digital del profesor universitario en la sociedad del conocimiento, se plantea la integración de la misma en su perfil profesional, y las funciones como desarrollo profesional docente. Las unidades de competencia digital, relacionadas con la función docente, investigadora y de gestión, se van integrando de forma secuencial y continua en la competencia digital; el nivel de dominio y el grado de complejidad alcanzado supondría uno de los indicadores de utilidad en la planificación de programas de formación continua del profesorado.

Desde que se inició el proceso de Bolonia, las universidades están realizando un gran esfuerzo por integrar la tecnología en la rutina diaria docente con el fin de mejorar la calidad de la enseñanza y adaptarse a las directrices que exige el Espacio de Educación Europeo Superior (Bárcena, Martín-Monje, y Jordano de la Torre, 2016). Una vía para conseguirlo ha sido la innovación educativa o innovación en el contexto académico (Sein-Echaluce, Fidalgo-Blanco y Alves, 2016). Gracias a ello, se han multiplicado los proyectos de innovación educativa dirigidos por instituciones

Los NOOC para la formación en competencias digitales del docente universitario. Una experiencia piloto en una Universidad Nacional de Educación a Distancia (UNED). Lourdes Pérez-Sánchez, María Jordano de la Torre y Ana María Martín-Cuadrado.

Página 3 de 35 
universitarias, con el objetivo de incorporar recursos en abierto, cursos $\mathrm{MOOC}$ que visibilicen el know how de la universidad (como es el caso de UNED Abierta). Algunos ejemplos representativos: la puesta en práctica de proyectos de innovación en el aula, dirigidos por docentes, con el objetivo de diseñar materiales en abierto o cursos SPOC (Small Private Online Course) que faciliten la comprensión y adquisición del contenido en experiencias concretas (Santamaría, 2014a); cursos MOOC para complementar los aprendizajes de los estudiantes en las asignaturas de grado (Farrán y Pérez, 2017; Pelayo et al., 2017) proyectos de innovación (Erasmus+), con el objetivo de utilizar la tecnología para mostrar diferentes formatos de uso didáctico (Martín-Cuadrado et al., 2017), entre otras cosas. En la UNED, en el año 2006 se implementó la I Estrategia de Innovación Educativa y aparecieron las redes de innovación docente, cursos específicos sobre docencia universitaria o apoyo de personal cualificado que prestaban servicio en los diferentes campus universitarios (Santamaría, 2014b). Diez años más tarde, y partiendo de los resultados más significativos de la experiencia realizada, se formaron equipos de trabajo con la consiguiente consolidación de líneas de trabajo, con lo que la UNED inicia la II Estrategia de Innovación Educativa. Su objetivo es doble. En primer lugar, potenciar la constitución, acreditación y consolidación de los Grupos de Innovación Docente (GID) para realizar investigación educativa fundamentada en las líneas estratégicas de la universidad; en segundo lugar, lograr que la investigación educativa forme parte del quehacer docente.

Esta inmersión del docente en el mundo de las tecnologías trae consigo una serie de repercusiones que alterara su forma de trabajar, su forma de investigar, de comunicarse, de formarse, de transmitir el conocimiento. A esto, hay que añadir el cambio que se produce en el rol del docente, que viene experimentándose en todos los niveles educativos desde finales del anterior milenio. Tal es así, que:

El profesor deja de ser fuente de todo conocimiento y pasa a actuar como guía de los alumnos, facilitándoles el uso de los recursos y las herramientas que necesitan para explorar y elaborar nuevos conocimientos y destrezas; pasa a actuar como gestor de la pléyade de recursos de aprendizaje y a acentuar su papel de orientador y mediador. (Salinas, 2004).

De forma más concreta, desempeñará papeles como el de tutor, orientador, ingeniero pedagógico, experto tecnólogo, diseñador de materiales didácticos, documentalista, evaluador, editor de documentos, calificativos establecidos por varios autores (De Vincenzi, 2012; Jordano de la Torre, 2009); Manzano Soto, Martín-Cuadrado, Sánchez García, Rísquez y Suárez Ortega, 2012)

Una vez dibujado el contexto educativo en el que nos encontramos, la competencia digital se podría describir como una de las competencias clave "que implica el uso creativo, crítico y seguro de las tecnologías de la información y la comunicación para alcanzar los objetivos relacionados con el trabajo, la empleabilidad, el aprendizaje, el uso del tiempo libre, la inclusión y participación en la sociedad" (INTEF, 2013a). Tal es su relevancia en el sistema educativo actual, que esta forma ya parte de las competencias básicas del docente. Se busca, por tanto, facilitar su dominio para favorecer el uso e integración total de las TIC en la educación, adecuando la

Los NOOC para la formación en competencias digitales del docente universitario. Una experiencia piloto en una Universidad Nacional de Educación a Distancia (UNED). Lourdes Pérez-Sánchez, María Jordano de la Torre y Ana María Martín-Cuadrado.

Página 4 de 35 
metodología didáctica a la nueva realidad educativa. Es por ello por lo que "El Marco Común de Competencia Digital Docente" (INTEF, 2013a) nace con la intención de ofrecer una referencia descriptiva que pueda servir como punto de salida para establecer los fines $u$ objetivos en los procesos de formación y en procesos de evaluación y acreditación. Forma parte tanto del "Plan de Cultura Digital en la Escuela" (INTEF, 2013b) como del "Marco Estratégico de Desarrollo Profesional Docente" (INTEF, 2013c), cuyo conjunto de proyectos son resultado del proceso de reflexión compartida que el Ministerio abrió con la participación de las CCAA y ponencias en las que también participan expertos externos y responsables de diversas unidades del MECD.

Con el fin de analizar y mejorar la capacitación tecnológica de los docentes universitarios en la actualidad, se vienen sucediendo una serie de iniciativas que analizan el nivel del profesorado universitario en este área mediante observatorios y matrices de valoración (Gisbert, Espuny y González, 2011; Gisbert Cervera, Martínez y Mon, 2016; Lázaro Cantabrana y Gisbert Cervera, 2015; Píriz Durán, 2015). Paralelamente, se están proponiendo iniciativas en diferentes comunidades como la catalana de cara a certificar el grado de conocimiento digital de la ciudadanía. De este modo, la "acTIC" (acreditació de competències en tecnologies de la informació i la comunicació). Gracias a este, cualquier ciudadano mayor de 16 años puede certificar su nivel tecnológico y presentarlo en empresas y la administración pública. Aunque su realización es telemática, es necesario presentarse físicamente en cualquiera de los más de 300 puntos repartidos por toda la geografía catalana. A nivel internacional, la European Computer Driving Licence $(E C D L)^{1}$, ha certificado ya a más de un millón de personas, traspasando fronteras incluso fuera de Europa.

Durante estos años, se ha estado trabajando con los descriptores que unas y otras instituciones han ido adaptando a sus propias necesidades. Si gracias a la UNESCO (Unesco, 2008) se comenzaron a marcar las primeras directrices hablando de competencias básicas que debe tener un docente a todos los niveles, la última se decanta más por trabajar en los diferentes ámbitos (Redecker, 2017). A continuación, se muestra un resumen de la evolución de estos documentos con las novedades que aporta cada uno con respecto a las competencias.

1

http://ecdl.org/

Los NOOC para la formación en competencias digitales del docente universitario. Una experiencia piloto en una Universidad Nacional de Educación a Distancia (UNED). Lourdes Pérez-Sánchez, María Jordano de la Torre y Ana María Martín-Cuadrado.

Página 5 de 35 
Tabla 1: Evolución seguida por las competencias digitales a lo largo de los diferentes documentos de trabajo (Elaboración propia).

\begin{tabular}{|c|c|c|c|c|}
\hline UNESCO, 2008 & DIGCOMP 1.02013 & $\begin{array}{c}\text { DIGCOMP 2.0, } \\
2016(\text { V.1) }\end{array}$ & $\begin{array}{c}\text { DIGCOMP 2.0, } \\
2017\end{array}$ & $\begin{array}{c}\text { DigCompEdu } \\
\text { (2017) }\end{array}$ \\
\hline \multirow[t]{3}{*}{\begin{tabular}{|l} 
1. Utilizar \\
tecnologías de la \\
información; \\
2. Buscadores, \\
analizadores y \\
evaluadores de \\
información; \\
3. Solucionar \\
problemas \\
4. Crear y producir \\
herramientas TIC. \\
5. Comunicar y \\
producir. \\
6. Responsables y \\
sostenibles.
\end{tabular}} & $\begin{array}{l}\text { 1. Información } \\
\text { 2. Comunicación } \\
\text { 3. Creación de } \\
\text { contenido } \\
\text { 4. Seguridad } \\
\text { 5. Resolución de } \\
\text { problemas }\end{array}$ & $\begin{array}{l}\text { 1. Información (y } \\
\text { alfabetización } \\
\text { digital) } \\
\text { 2. Comunicación (y } \\
\text { colaboración) } \\
\text { 3. Creación de } \\
\text { contenido (digital) } \\
\text { 4. Seguridad } \\
\text { 5. Resolución de } \\
\text { problemas. }\end{array}$ & $\begin{array}{l}\text { 1. Información (y } \\
\text { alfabetización } \\
\text { digital) } \\
\text { 2. Comunicación (y } \\
\text { colaboración) } \\
\text { 3. Creación de } \\
\text { contenido (digital) } \\
\text { 4. Seguridad } \\
\text { 5. Resolución de } \\
\text { problemas. }\end{array}$ & $\begin{array}{l}\text { 1. Área } 1 \text { entorno } \\
\text { profesional; } \\
\text { 2. Área } 2 \text { fuentes, } \\
\text { creación y } \\
\text { distribución de } \\
\text { recursos digitales; } \\
\text { 3. Área } 3 \\
\text { administrar y } \\
\text { orquestar el uso de } \\
\text { herramientas } \\
\text { digitales } \\
\text { 4. Área } 4 \\
\text { herramientas y } \\
\text { estrategias digitales } \\
\text { para mejorar la } \\
\text { evaluación; } \\
5 \text {. Área } 5 \text { de } \\
\text { herramientas } \\
\text { digitales para } \\
\text { empoderar a los } \\
\text { estudiantes; } \\
6 \text {. Área } 6 \text { facilitar la } \\
\text { competencia digital } \\
\text { de los alumnos. }\end{array}$ \\
\hline & & & $\begin{array}{l}\text { Se añaden } 8 \text { niveles } \\
\text { de dificultad para } \\
\text { cada competencia }\end{array}$ & \\
\hline & & & $\begin{array}{l}\text { Se añaden ejemplos } \\
\text { de uso por cada } \\
\text { ámbito }\end{array}$ & \\
\hline
\end{tabular}

Llegados a este punto, es preciso tener clara la definición de dimensión (Redecker, 2017), a saber:

1. Dimensión 1 - área competencial (por ejemplo: Información)

2. Dimensión 2 - competencia como tal / descriptores (navegación, búsqueda y selección de datos, información y contenidos)

3. Dimensión 3 - niveles de dificultad por cada competencia (se pasa de 3 a los 8 niveles de dificultad)

4. Dimensión 4 - conocimientos y destrezas que dependen de cada competencia

5. Dimensión 5 - ejemplos de aplicación en cada ámbito, por ejemplo, el educativo / docentes. 


\section{El formato NOOC en la capacitación docente a lo largo de la vida.}

Aunque algunos autores datan el origen de los MOOC en Canadá en el año 2008 (Sangrà, González-Sanmamed y Anderson, 2015), algunas instituciones como TESOL International llevan organizando cursos masivos en abierto para formar al profesorado de lenguas en nuevas tecnologías desde el año 2001 (Elizabeth Hanson-Smith, 2004). Estos, a diferencia de los anteriores y otros formatos de cursos en abierto (Fernández \& Webster, 2014) como los Open Courseware (OCW), carecían de plataforma como tal y hacían uso de cualquier tipo de herramienta que permitiera la interacción online, inclinándose hacia los grupos de $Y a_{h o o^{2}}$ en los primeros años 0 a wikis y redes sociales en las últimas ediciones. Desde aquella época se ha evolucionado mucho desde la formación reglada y certificada hacia tendencias más abiertas de concebir la educación y la investigación como tal (Czerniewicz, Deacon, Glover \& Walji, 2017)

Si hace relativamente poco tiempo, este tipo de cursos irrumpieron en la universidad a nivel internacional (Fidalgo-Blanco et al., 2016; Glass, Shiokawa-Baklan, \& Saltarelli, 2016; Poy \& Gonzales-Aguilar, 2014), a día de hoy, están llegando a otros niveles de la educación o incluso a entornos empresariales (Baggaley, 2013; Lirsa, Cécile Dejoux, Charrière-Grillon, 2016). Esto se ha hecho posible gracias a que se ha facilitado acceso a Internet desde cualquier tipo de dispositivo y a un posible abaratamiento de costes debido a la flexibilidad y virtualidad de los mismos. Desde su integración en la educación actual, se han desarrollado diferentes plataformas para atender sus necesidades específicas tales como su usabilidad y el número de personas al que va dirigido, e incluso se han ido clasificando atendiendo a diferentes finalidades y formato (Cabero Almenara, 2015; Fidalgo-Blanco et al., 2016; García Aretio, 2015; Vázquez Cano y López Meneses, 2015).

Pasada casi una década de la creación de los primeros MOOC, aparece un nuevo formato de curso en abierto, mucho más corto en el tiempo, flexible y que pretende tratar unos de los mayores problemas de los MOOC como son la alta tasa de abandono. Si los MOOC estaban pensados para una dedicación total de unas 10 horas, en este caso se vienen planteando NOOC o Nano cursos de 3 horas (Junta de Andalucía, 2017), lo suficiente para formarse en aspectos muy pequeños de nuestra capacitación laboral que se pudiera necesitar en ciertos momentos.

Si de los MOOC existe ya una bibliografía considerable y asentada ya, de los nano cursos o NOOC apenas si se han realizado estudios empíricos que arrojen resultados sobre su funcionamiento. La primera referencia a ellos data de 2013 entre los ocho famosos tipos de MOOC que aparecen en la taxonomía de Clark (Clark, 2013) como mini-MOOC o Micro-NOOC (Coakley, Garvey y O'Neill, 2016). Lo que se pretende con estos nuevos formatos es poder a asistir a cursos en línea desde cualquier lugar y en cualquier momento (Campal, 2017; Junta de Andalucía, 2017; Banderas Navarro, 2017)

Los NOOC para la formación en competencias digitales del docente universitario. Una experiencia piloto en una Universidad Nacional de Educación a Distancia (UNED). Lourdes Pérez-Sánchez, María Jordano de la Torre y Ana María Martín-Cuadrado.

Página 7 de 35 


\section{Algunos ejemplos de MOOC y NOOC involucrados en la formación de la capacitación digital docente.}

A nivel nacional el único $\mathrm{NOOC}$ dedicado a las competencias digitales docentes está diseñado e impartido por el Instituto Nacional de Tecnología para la Formación del Profesorado (INTEF, 2017), que aparece ofertado cada año junto a otros cursos similares $^{3}$. Sin embargo, en el terreno universitario y bajo las premisas del DigComp 2.1 no se han creado apenas cursos todavía. La siguiente tabla muestra a continuación ejemplos de otros obtenidos a través de diferentes bases de datos de MOOC y otros cursos en abierto:

Tabla no 2: Ejemplos de formación MOOC en diferentes plataformas internacionales. (Elaboración propia)

\begin{tabular}{|c|c|c|c|}
\hline Título & Institución & $\begin{array}{l}\text { Plataforma } \\
\text { empleada }\end{array}$ & Duración \\
\hline University Teaching ${ }^{4}$ & $\begin{array}{l}\begin{array}{l}\text { University of Hong Kong } \\
\text { (China) }\end{array} \\
\end{array}$ & Coursera & 6 semanas \\
\hline Teaching Adult Learners ${ }^{5}$ & $\begin{array}{l}\text { North Metropolitan TAFE } \\
\text { (Australia) }\end{array}$ & Open2 Study & 2 semanas \\
\hline Learning in the Network $\mathrm{Age}^{6}$ & $\begin{array}{|ll|}\begin{array}{l}\text { University of Southampton } \\
\text { (Reino Unido) }\end{array} & \\
\end{array}$ & Future Learn & 2 semanas \\
\hline $\begin{array}{l}\text { Profesionales ecompetentes. } \\
\text { Claves, estrategias y } \\
\text { herramientas para innovar en } \\
\text { red }^{7}\end{array}$ & $\begin{array}{l}\text { Universidad de Málaga y } \\
\text { Universidad de Loja (Brasil) }\end{array}$ & Miriadax & 8 semanas \\
\hline
\end{tabular}

Como se puede observar, la mayoría tratan los temas de la formación docente y las competencias digitales por separado, y algunas de ellas no están directamente relacionadas con el profesorado universitario, pero si la enseñanza de adultos del siglo XXI. En ocasiones, se ha tomado algún caso de enseñanza en tecnologías en la universidad en general, pero no relacionado directamente con el profesorado. Algunos autores apuntan hacia profesorado a tiempo completo como el $50 \%$ de los suscritos a estos MOOC, que puede ser debido a una forma de actualización profesional rápida y flexible, que además se puede certificar como se requiere en la mayoría de las instituciones educativas para poder promocionar a nivel profesional (Glass et al., 2016; Poy y Gonzales-Aguilar, 2014).

\footnotetext{
$3 \quad$ http://mooc.educalab.es/

4 https://www.coursera.org/learn/university-teaching

5 https://www.mooc-list.com/course/teaching-adult-learners-open2study

$6 \quad$ https://www.futurelearn.com/courses/learning-network-age

7 https://miriadax.net/web/profesionales-ecompetentes-claves-estrategias-y-herramientaspara-innovar-en-red
}

Los NOOC para la formación en competencias digitales del docente universitario. Una experiencia piloto en una Universidad Nacional de Educación a Distancia (UNED). Lourdes Pérez-Sánchez, María Jordano de la Torre y Ana María Martín-Cuadrado.

Página 8 de 35 


\section{Experiencia piloto para la formación del área informacional}

\subsection{Metodología}

Hasta la fecha, algunos MOOC se han decantado por proporcionar un buen diseño de contenidos, originales y diseñados para que el suscriptor los adquiera de forma rápida y eficaz, como es el caso de los cMOOC (Moral Pérez y Villalustre Martínez, 2015). Por otro lado, los hay que prefieren hacer uso de lo que ya hay en la red para plantear tareas ad hoc para ser realizadas de forma individual o de manera grupal, como es el caso de los XMOOC (Cabero Almenara, 2015; Fidalgo-Blanco et al., 2016). En el caso de los MOOC que en este estudio se presentan, se han fundido ambas tipologías, ya que se ha considerado que es lo más acertado teniendo en cuenta la literatura analizada.

Unos de los problemas que se viene planteando en cuanto a los MOOC es la masificación de los mismos y la metodología utilizada a base de ensayo-error en las pruebas de evaluación. En el caso de los NOOC que aquí se presentan, esta carencia se ha tratado de suplir mediante test previos de autoevaluación que ayudan a conocer al estudiante su propio conocimiento del área en cuestión de forma que se personalice de alguna forma su proceso de aprendizaje. Este tipo de autoevaluación se asemeja a los propuestos de manera aislada por comunidad andaluza, con su "Herramienta de autodiagnóstico en competencias digitales" (Junta de Andalucía, 2016) o la comunidad vasca (Ikanos, 2015). Los test propuestos para los NOOC de este estudio incluyen preguntas directamente relacionadas con los tres niveles marcados por la Unión Europea en la primera versión de DigComp (Ferrari, 2013) y que llevarán al interesado a cursar uno u otro nivel dependiendo del resultado. De cara a la segunda versión de estos NOOC se esté realizando la adaptación a la versión aprobada en mayo de 2016 (Pérez-Escoda y González Fernández-Villacencio, 2016).

La mayoría de los MOOC presentan una estructura bastante rígida (Pardos \& Schneider, 2013). En primer lugar, una introducción, que se compone a su vez de una presentación, grabada en video por uno de los profesores acompañada de algunas lecturas complementarias. Luego se muestran los contenidos, estructurados en varios módulos formados por pequeñas cápsulas de información en texto o formato audiovisual. Estos, van seguidos de algún tipo de evaluación, que puede ser de varios tipos entre los que destacan la autoevaluación o la resolución de problemas/ casos evaluados por pares, que suelen ser los compañeros de estudio. Normalmente suele haber un foro, que puede ser a su vez el receptor de algunas de las actividades propuestas, y en el caso de los xMOOC se suelen enriquecer con múltiple presencia en redes sociales a cargo de los propios estudiantes incluso. De cara a la certificación, habría que tener en cuenta la obtención de "badgets" de cara a la certificación final y

Los NOOC para la formación en competencias digitales del docente universitario. Una experiencia piloto en una Universidad Nacional de Educación a Distancia (UNED). Lourdes Pérez-Sánchez, María Jordano de la Torre y Ana María Martín-Cuadrado.

Página 9 de 35 
de cómo estos son tratados y dispuestos a lo largo de todo el MOOC (Kopp \& Ebner, 2017).

En el caso de los NOOC de este estudio se ha seguido una estructura similar a la mencionada anteriormente, teniendo en cuenta que para ser certificado en cada una de las áreas competenciales se debe haber demostrado previamente tener los conocimientos requeridos en cada uno de los tres niveles de dificultad (Jordano, Martín-Cuadrado, y Pérez-Sánchez, 2017). De esta forma, la persona interesada deberá realizar o haber demostrado conocer las tres competencias de las que se compone el área competencial de la información, como se muestra en la figura 1 más adelante.

\subsection{Descripción del proyecto}

Siguiendo las pautas que se describen en los documentos anteriormente mencionados, se procedió a diseñar los cursos NOOC teniendo en cuenta las competencias comprendidas dentro de cada una de las áreas competenciales, tomando como base los descriptores que aparecen en DigComp 2.0 (INTEF, 2013a) y adaptándolas a las necesidades propias de la formación docente universitaria, incluyendo a su vez la investigación:

I.- Información: identificar, localizar, recuperar, almacenar, organizar y analizar la información digital.

II.- Comunicación: comunicar, compartir recursos, conectar y colaborar, interactuar y participar en comunidades.

III.- Creación de contenidos: crear y editar contenidos nuevos, producciones artísticas multimedia.

IV.- Seguridad: Protección personal, de datos, identidad digital, uso de seguridad, uso seguro y sostenible.

V.- Resolución de problemas: identificar necesidades y recursos digitales, tomar decisiones, resolver problemas técnicos y el uso creativo de la tecnología,....

En este sentido, desde la UNED, a través del Instituto Universitario de Educación a Distancia (IUED), se ha diseñado la propuesta que aquí se presenta, ciñéndose únicamente al área competencial de la información para esta primera edición. Ésta, a su vez, está conformada por tres competencias:

1.- Navegación, búsqueda y filtrado de información.

2.- Evaluación de información.

3.- Almacenamiento y recuperación de información.

Cada una de las competencias informacionales a trabajar está compuesta a su vez de tres niveles de dificultad: Básico, Medio y Avanzado. Una vez realizada la prueba de autoevaluación, se le recomienda al interesado inscribirse en uno u otro nivel dependiendo del nivel alcanzado en cada una de las competencias de área. Esta decisión es personal y autónoma y está basada en la autoevaluación, tan defendida

Los NOOC para la formación en competencias digitales del docente universitario. Una experiencia piloto en una Universidad Nacional de Educación a Distancia (UNED). Lourdes Pérez-Sánchez, María Jordano de la Torre y Ana María Martín-Cuadrado.

Página 10 de 35 
por Bolonia desde sus comienzos (Rodríguez Gómez, Ibarra Sáiz, y García Jiménez, 2013). El estudiante seguirá el camino elegido hasta completar el nivel avanzado de cada categoría, realizando la práctica final solicitada al término del mismo.

El siguiente gráfico describe de manera visual el itinerario recomendado dependiendo del nivel alcanzado en dicha prueba, tal y como he descrito anteriormente:

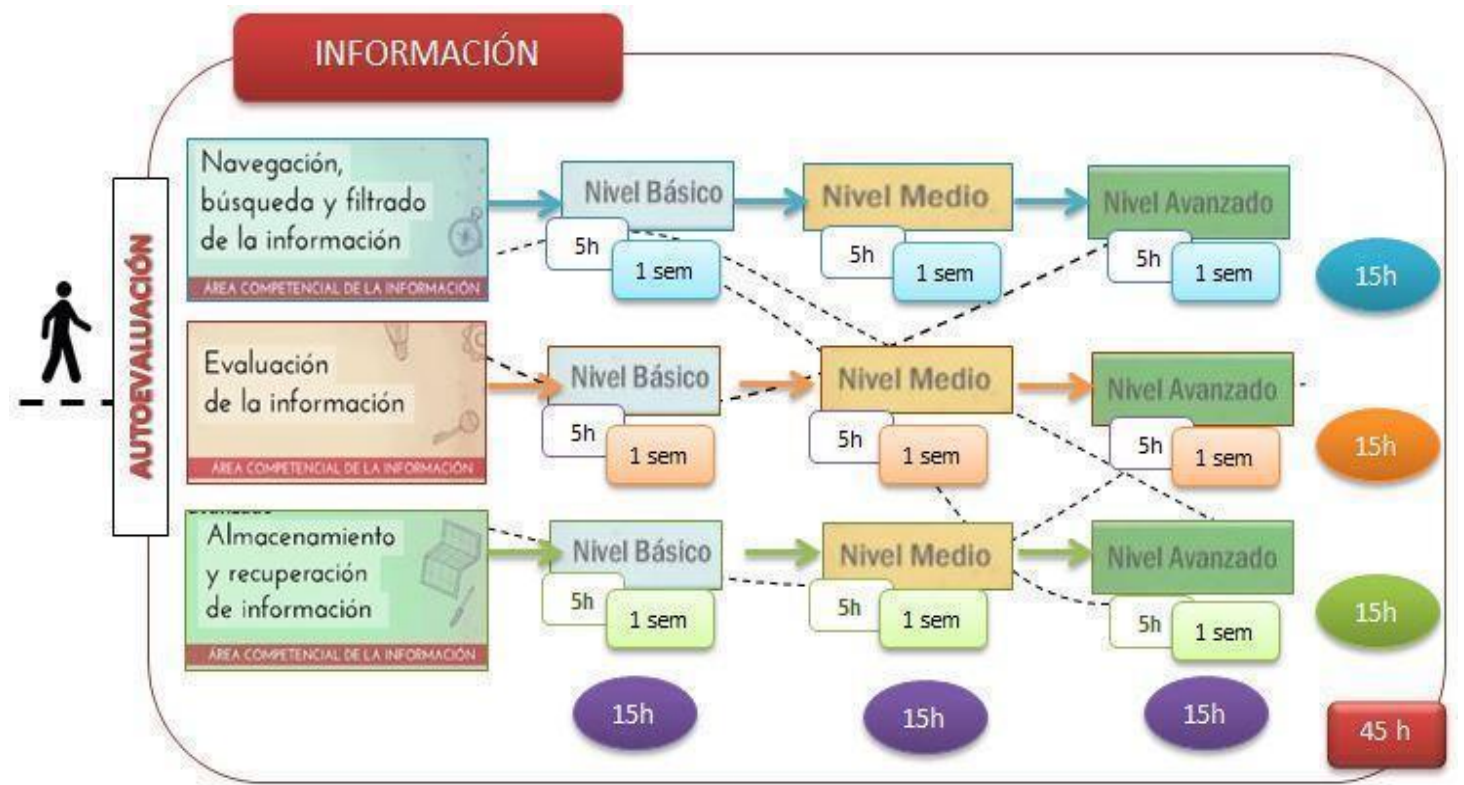

Figura 1: Representación global de la estructura de la propuesta formativa del área competencial de la Información. (Elaboración propia)

Como se puede observar, cada NOOC contiene cinco horas de formación aproximadamente, impartido en una semana de formación como mínimo, dependiendo de cada estudiante, ya que se dispondrá de dos semanas para completar todas las actividades propuestas para cada uno.

A partir de cada una de las competencias, se aprenderán conceptos, procedimientos y aptitudes, distribuidos en tres niveles de dificultad. Superar uno o varios permitirá al estudiante lograr diferentes acreditaciones, hasta lograr la certificación final después de superar la elaboración de una prueba final que demuestre que ha adquirido todo lo necesario para ser certificado en el área.

Una vez finalizados estos cursos o NOOC el estudiante habrá aprendido a navegar de forma adecuada a sus intereses, aplicando criterios de calidad y siendo capaces de gestionar la información obtenida de forma adecuada en el contexto de la enseñanza universitaria docente e investigadora.

La primera edición de los cursos tuvo lugar en el mes de noviembre de 2016, a través UNED Abierta ${ }^{8}$, dentro de los cursos ofertados por el Vicerrectorado de Formación Permanente lugar donde se da visibilidad a todos los cursos en abierto de la citada

Los NOOC para la formación en competencias digitales del docente universitario. Una experiencia piloto en una Universidad Nacional de Educación a Distancia (UNED). Lourdes Pérez-Sánchez, María Jordano de la Torre y Ana María Martín-Cuadrado.

Página 11 de 35 
institución. Todos ellos han utilizado la plataforma $\mathrm{EdX} \mathrm{X}^{9}$ para su creación, software de código abierto muy conocido entre otros como Coursera o MiriadaX.

Los nueve cursos NOOC del área competencial de la Información, para trabajar sus tres competencias, se impartieron en las fechas que se muestran en la tabla 3.

Tabla 3: Esquema de la organización temporal de los NOOC presentados.

\begin{tabular}{ccc}
\hline $\begin{array}{c}\text { Navegación, búsqueda y filtrado de información. } \\
\text { Nivel Básico } \\
18 \text { de Noviembre a } 28 \text { de Diciembre de 2016. }\end{array}$ & Nivel Avanzado \\
\hline $\begin{array}{r}\text { Evaluación de la información. } \\
\text { Nivel Básico } \\
16 \text { de Enero a } 26 \text { de Febrero de 2017. }\end{array}$ & Nivel Avanzado \\
\hline Almacenamiento y recuperación de la información & Nivel Intermedio & Nivel Avanzado \\
Nivel Básico & & \\
\hline
\end{tabular}

Como se puede observar, los diferentes niveles de cada competencia se abrieron y cerraron en el mismo intervalo de tiempo. Se dejó una semana más de margen a cada curso en caso de que algún interesado necesitará realizar más de un nivel. De cara a ediciones futuras, los contenidos de cada curso se irán revisando y adaptando de acuerdo con las siguientes versiones del DigComp, en especial el dedicado a la educación (DigCompEdu).

\subsection{Estructura de los cursos NOOC.}

Todos los cursos diseñados para las diferentes competencias y en los diferentes niveles de dificultad cuentan con la misma estructura, con el fin de ofrecer al estudiante una línea de aprendizaje coherente y homogénea, facilitando la navegación por el contenido de cada curso.

De esta forma, cada unidad comprende los siguientes apartados:

- Módulo de presentación. En este módulo se incluyen tres elementos fundamentales para establecer las bases del buen desarrollo del curso:

a) Encuesta inicial de cumplimiento voluntario y que pretende recabar información sobre la formación, el nivel de estudios, experiencia previa en cursos on-line, y sobre cuáles son los motivos y expectativas del futuro estudiante de cada competencia y nivel (Ver Anexo I, p. 31).

Los NOOC para la formación en competencias digitales del docente universitario. Una experiencia piloto en una Universidad Nacional de Educación a Distancia (UNED). Lourdes Pérez-Sánchez, María Jordano de la Torre y Ana María Martín-Cuadrado.

Página 12 de 35 
b) Instrucciones previas que ayudarán al estudiante a moverse y seguir el curso sin problemas.

c) Presentación del foro general de dudas, que estará presente durante todo el proceso y mediante el cual se pueden plantear sus dudas sobre el funcionamiento del curso, tanto de tipo técnico como de los propios contenidos del curso.

- Estructura del contenido a trabajar, dividida en cinco unidades de contenidos, que a su vez están formadas por los siguientes elementos:

a) Objetivos: aquellas cuestiones y logros que se pretenden alcanzar con la superación de cada unidad de contenido.

b) Contenidos: material didáctico para la lectura y estudio por parte de los estudiantes.

c) Actividades prácticas:

a. De ensayo.

b. Cuestionarios.

c. Foros.

d) Para Saber más.

- Actividad final, a modo de portfolio de actividades realizadas durante el curso, que demuestre de manera resumida y rápida que se han realizado con éxito las prácticas propuestas durante el mismo.

A esta actividad, se añade la encuesta final, de cumplimentación voluntaria, con la que se pretenden conocer las impresiones del estudiante con el fin de mejorar futuras ediciones. En esta se aparecen preguntas relacionadas con el cumplimiento de expectativas, metas alcanzadas, utilización de recursos, o la calidad de los mismos (ver Anexo II, p. 32).

\subsection{La autoevaluación}

Una de las novedades de esta propuesta formativa es la posibilidad de realizar una autoevaluación previa a la inscripción en cada una de las áreas competenciales. De esta forma, se puede llegar a conocer con anterioridad el nivel en el que se encuentra en tanto competencias digitales básicas, en todos y cada uno de los niveles de dificultad plateados (básico, intermedio y avanzado).

Esta autoevaluación es voluntaria, por un lado, ya que únicamente deberán realizarla aquellos que deseen conocer su nivel previamente; y por otra parte, es orientativa, ya que su resultado le proporciona una idea aproximada del nivel de conocimiento que el interesado posee. Además, en base a las puntuaciones obtenidas, se ofrecen una serie de recomendaciones en cuanto al proceso de aprendizaje a seguir. Consejos que podrían tomarse en consideración o no por parte de la persona interesada en realizar alguno de los cursos.

Los NOOC para la formación en competencias digitales del docente universitario. Una experiencia piloto en una Universidad Nacional de Educación a Distancia (UNED). Lourdes Pérez-Sánchez, María Jordano de la Torre y Ana María Martín-Cuadrado.

Página 13 de 35 
El total de cuestionarios de autoevaluación son, por tanto, tres, tantos como competencias disponibles a trabajar. Uno por cada nivel de dificultad de cada una de las tres competencias a trabajar. Todos ellos constan de preguntas cerradas sobre algunas de las herramientas e indicadores (Anexo III, p. 33) más importantes de los cursos y sus respuestas utilizan la escala tipo Likert de cuatro puntos. La siguiente tabla muestra un ejemplo del tipo de respuesta que se pondría encontrar.

Tabla 4: Respuestas incluidas en escala de Likert para los cuestionarios de autoevaluación.

\begin{tabular}{|c|c|c|c|}
\hline 1 & 2 & 3 & 4 \\
\hline Desconozco. & Conozco y utilizo. & Conozco casi todas. & Conozco todas. \\
\hline 1 & 2 & 3 & 4 \\
\hline Los desconozco. & Conozco algunos. & Conozco casi todos. & $\begin{array}{l}\text { Conozco todos y realizó } \\
\text { estas tareas a menudo. }\end{array}$ \\
\hline 1 & 2 & 3 & 4 \\
\hline $\begin{array}{l}\text { No lo he realizad } \\
\text { nunca. }\end{array}$ & $\begin{array}{l}\text { Sé que se puede } \\
\text { realizar, pero no lo he } \\
\text { hecho. }\end{array}$ & $\begin{array}{l}\text { Lo he realiz } \\
\text { algunas veces. }\end{array}$ & $\begin{array}{l}\text { Lo utilizo con mucha } \\
\text { frecuencia. }\end{array}$ \\
\hline 1 & 2 & 3 & 4 \\
\hline $\begin{array}{l}\text { No le he prestad } \\
\text { nunca atención. }\end{array}$ & $\begin{array}{l}\text { Conozco su importancia } \\
\text { y a veces me he } \\
\text { preocupado por estos } \\
\text { temas. }\end{array}$ & $\begin{array}{l}\text { Conozco y } \\
\text { ocasionalmente. }\end{array}$ & $\begin{array}{l}\text { Soy consciente de ello y } \\
\text { siempre estoy pendiente. }\end{array}$ \\
\hline 1 & 2 & 3 & 4 \\
\hline $\begin{array}{l}\text { o lo he realizi } \\
\text { unca. }\end{array}$ & $\begin{array}{l}\text { Lo he visto instalar, pe } \\
\text { no lo he hecho. }\end{array}$ & $\begin{array}{l}\text { Lo he instalado } \\
\text { vez con ayuda. }\end{array}$ & $\begin{array}{l}\text { a Lo instalo si } \\
\text { ayuda. }\end{array}$ \\
\hline
\end{tabular}

Las recomendaciones para cada nivel son las siguientes:

\section{- Nivel básico:}

- Si ha obtenido una puntuación inferior a 15, sería recomendable que realizase este curso, nivel BÁsı́CO.

- Si ha obtenido una puntuación superior a 15, probablemente sea de mayor interés acudir a un nivel superior, ya sea MEDIO O AVANZADO.

- Cada uno de los cursos NOOC, de cada competencia y cada nivel tiene una duración de 5 horas de trabajo autónomo para el estudiante.

\section{- Nivel intermedio:}

- Si ha obtenido una puntuación inferior a $\mathbf{2 0}$, sería recomendable que realizase este curso o el de nivel BÁsıco.

- Si conoce los elementos presentados anteriormente obtenido una puntuación superior a 20, probablemente sea de mayor interés acudir a un nivel superior O AVANZADO.

\section{- Nivel avanzado:}

Los NOOC para la formación en competencias digitales del docente universitario. Una experiencia piloto en una Universidad Nacional de Educación a Distancia (UNED). Lourdes Pérez-Sánchez, María Jordano de la Torre y Ana María Martín-Cuadrado.

Página 14 de 35 
- Si ha obtenido una puntuación inferior a $\mathbf{2 0}$, sería recomendable que realizase este curso o el de nivel MEDIO.

- Si conoce los elementos presentados anteriormente obtenido una puntuación superior a 20, este curso podrá servirle para afianzar dichos conocimientos y compartir con otros usuarios sus experiencias.

Dado que la realización de estos cuestionarios de autoevaluación era totalmente opcional, se muestra a continuación un gráfico con los porcentajes de participación en el mismo.

Como ya hemos mencionado anteriormente, estos cuestionarios de autoevaluación son de carácter voluntario. A continuación, se muestra el nivel de participación de los usuarios en los diferentes cursos, en tanto la realización de los referidos cuestionarios.

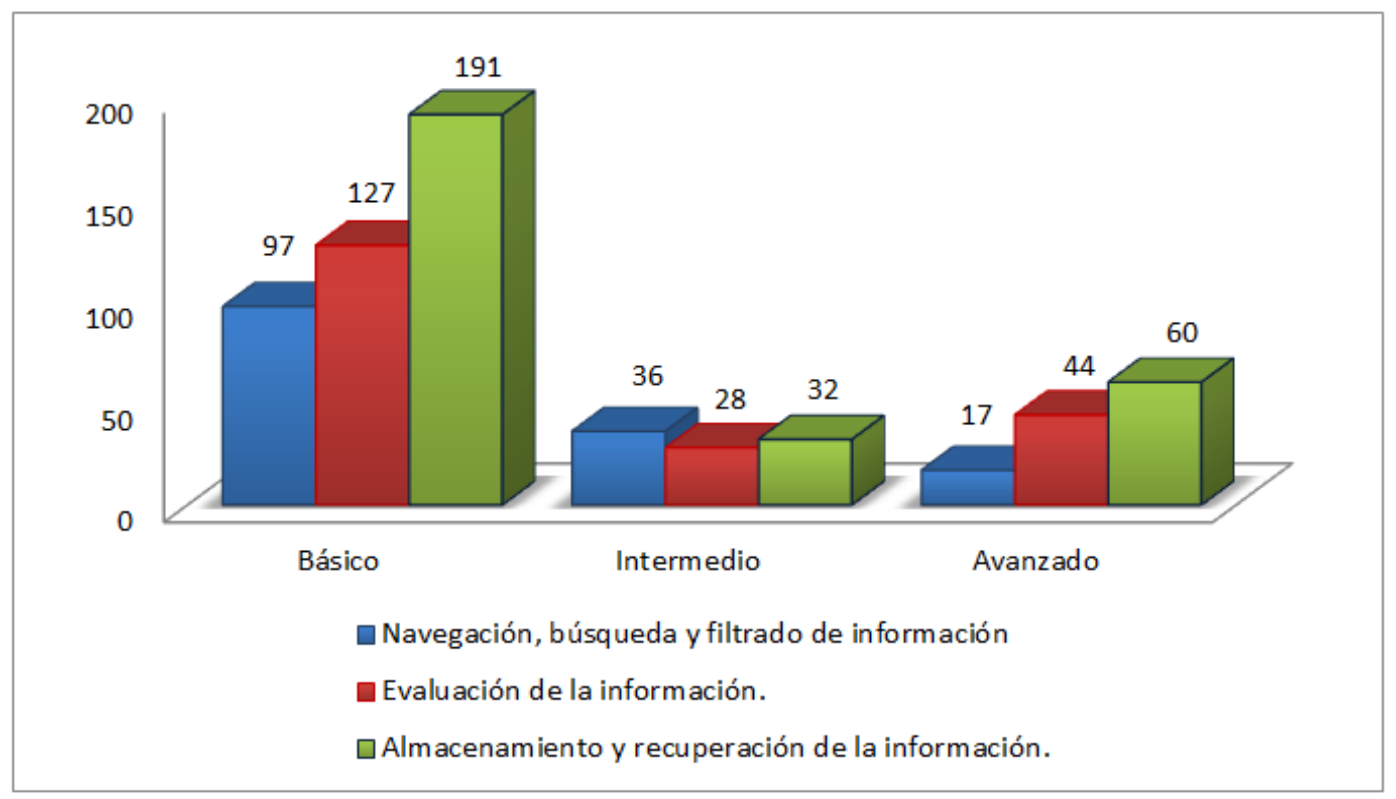

Gráfico 1: Número de cuestionarios de evaluación realizados por niveles de dificultad, en las tres competencias trabajadas.

Como se puede observar en la gráfica, en todos los cursos en su nivel básico, destaca una mayor participación en la realización del cuestionario de autoevaluación. Esto podría ser debido a que los usuarios que se describen con un nivel más bajo en su competencia digital básica en cualquiera de las tres áreas tienen una mayor disposición a autoevaluarse. A medida que esa autopercepción es más positiva, y el usuario se considera más competente en niveles superiores, el número de usuarios que realizan los cuestionarios de autoevaluación se reduce ostensiblemente.

\subsection{Datos de matriculación}

Como ya había indicado anteriormente, una de las principales características de esta propuesta formativa, es la posibilidad con la que los estudiantes cuentan de poder inscribirse en aquel nivel de dificultad de la competencia elegida, según sus propios criterios. La siguiente ilustración muestra el total de estudiantes matriculados por nivel dentro de cada área competencial o curso NOOC.

Los NOOC para la formación en competencias digitales del docente universitario. Una experiencia piloto en una Universidad Nacional de Educación a Distancia (UNED). Lourdes Pérez-Sánchez, María Jordano de la Torre y Ana María Martín-Cuadrado.

Página 15 de 35 


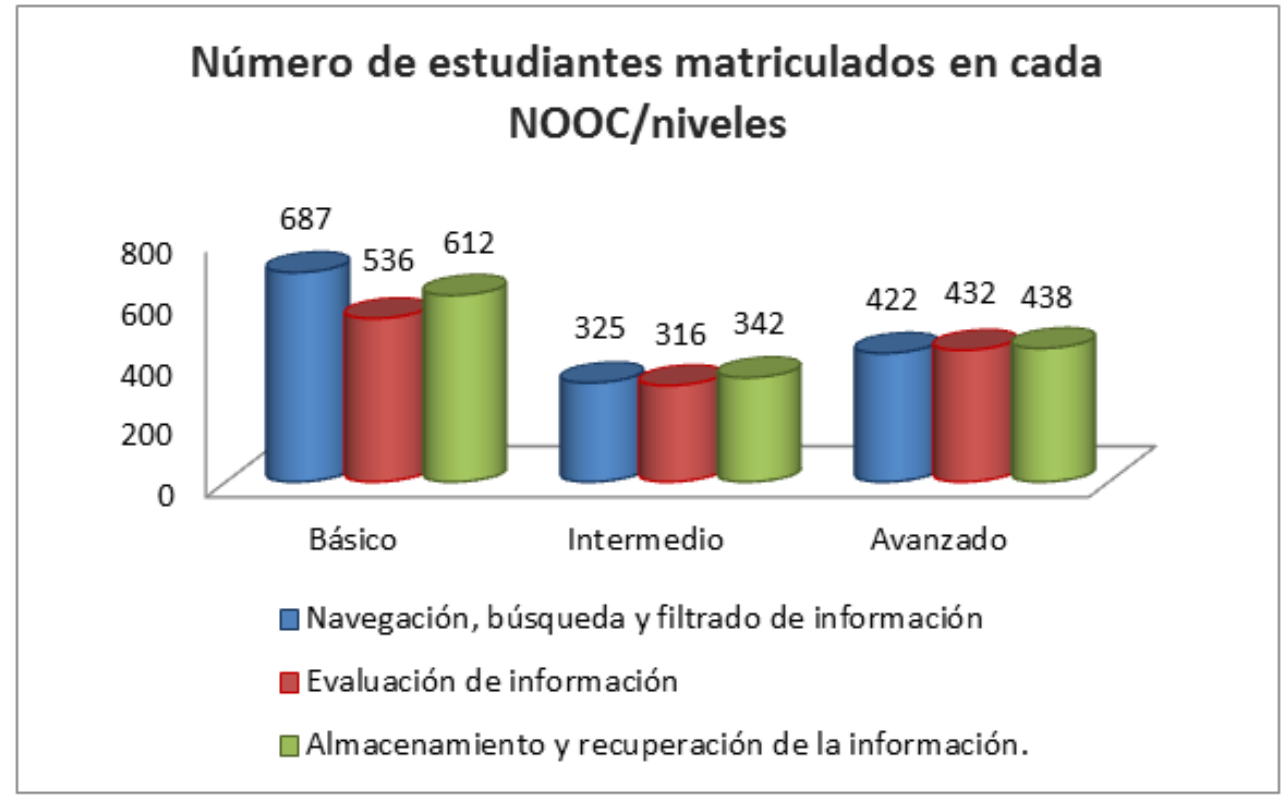

Gráfico 2: número de estudiantes matriculados en cada NOOC/nivel de dificultad.

Tal y como se observa en la gráfica, existe una gran diferencia entre el número de matriculados en el nivel básico de cualquiera de las tres competencias, con respecto a los matriculados en los otros dos niveles. Esto podría deberse a varias razones: exceso de motivación inicial que luego se fue perdiendo, en caso de haberse querido registrar en los tres niveles; nivel incipiente de la mayoría de las personas interesadas en realizar estos cursos, o falta de tiempo para realizar los tres niveles en caso de haberlos necesitado. De cara a otras ediciones se tratará de dar respuesta a estos interrogantes.

Sea como fuere, se deduce que el nivel de formación o capacitación en competencias digitales básicas del profesorado universitario interesado en realizar este tipo de cursos se sitúa a un nivel bajo o básico. De estos usuarios de nivel inicial, unos pasarán al nivel intermedio, otros al nivel avanzado de forma directa, o bien tan solo realizarán este nivel. Cada uno se formará en o hasta el nivel que consideren oportuno o necesario. En segunda instancia, otros estudiantes o usuarios podrán comenzar la formación en el nivel intermedio y seguir al avanzado, o bien entrar directamente al nivel de más alta dificultad.

\subsection{Descripción de los participantes}

De cara a la mejora de los contenidos y actividades contenidas en estos cursos en ediciones posteriores, se procede ahora a comentar los datos recogidos según el tipo de participante, de vital importancia en cursos de naturaleza tan heterogénea. De alguna forma, los siguientes datos recogidos de las encuestas realizadas durante el curso vienen a corroborar, de alguna forma, resultados derivados de otros estudios realizados hasta la fecha (Glass et al., 2016; Kopp y Ebner, 2017; Sosa Díaz, Díaz Flores, y López Andrada, 2014). Estos se refieren a características derivadas del género, edad, nacionalidad, nivel de formación, dedicación a la docencia y las áreas

Los NOOC para la formación en competencias digitales del docente universitario. Una experiencia piloto en una Universidad Nacional de Educación a Distancia (UNED). Lourdes Pérez-Sánchez, María Jordano de la Torre y Ana María Martín-Cuadrado.

Página 16 de 35 
de conocimiento en la que desempeñan su labor docente en caso afirmativo, analizándolos curso por curso:

\section{- Navegación, búsqueda y filtrado de información}

A pesar de ser este el curso más básico en lo que a contenidos se refiere, basado en la búsqueda de información académica en diferentes formatos, fue el que captó un mayor número de matriculados. Destaca un mayor número de mujeres matriculadas respecto al de hombres. El rango de edad mayoritario se centra entre los 45-54, protagonizado por personas que buscan reciclarse y ponerse al día en materia de tecnología educativa y actualizarse en esta competencia digital. Destacar también, que hay una cantidad importante de docentes y profesionales de edad superior a 55 años que entran en este mundo digital con el mismo fin, actualizarse o formarse para estar al día.

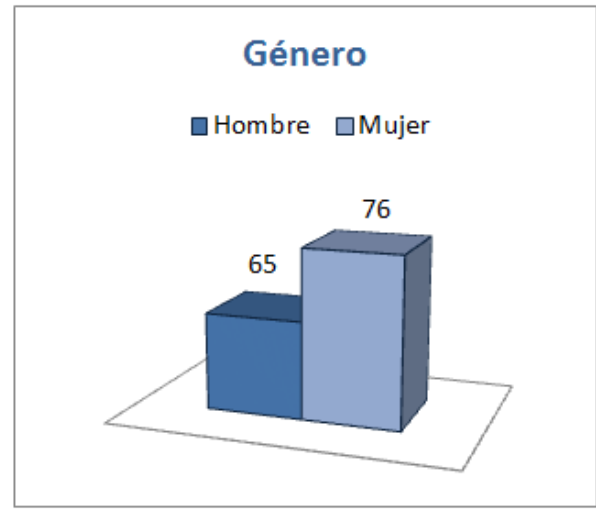

Gráfico 3: Distribución de los usuarios matriculados para el estudio de la competencia de Navegación, según el género.

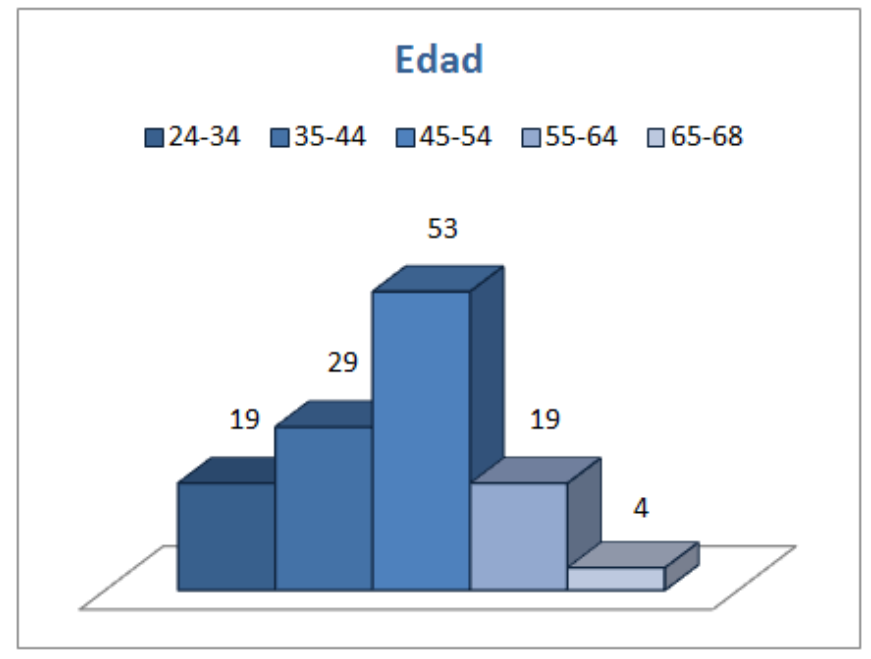

Gráfico 4: Distribución de los usuarios matriculados para el estudio de la competencia de Navegación, según el intervalo de edad.

La nacionalidad predominante en esta área de la navegación y búsqueda de información es la española, seguida de la argentina, aunque también se han registrado otras como la brasileña, británica, colombiana, ecuatoriana, hondureña, mexicana, portuguesa, venezolana, chilena y salvadoreña.

Una de las preocupaciones iniciales de este proyecto, y donde radica la singularidad de estos NOOC, es precisamente el estar dirigidos a personal docente universitario, en oposición de la finalidad de otros NOOC que han convivido durante la primera edición, enfocados a profesorado de la enseñanza preuniversitaria. Todo esto se indicó en la publicidad y al inicio de cada curso, para que además llegara a personal en activo, y, según demuestran los resultados, se han confirmado las expectativas. La mayoría de los usuarios eran docentes y se enmarcaban en la enseñanza universitaria. Una de las razones del descenso de alumnos a menudo que avanzan los niveles, podría ser precisamente el haberse inscrito en un curso que no cumplía sus expectativas, por estar directamente relacionado con temas académicos y de investigación que atañen más a este gremio que a otros.

Los NOOC para la formación en competencias digitales del docente universitario. Una experiencia piloto en una Universidad Nacional de Educación a Distancia (UNED). Lourdes Pérez-Sánchez, María Jordano de la Torre y Ana María Martín-Cuadrado.

Página 17 de 35 


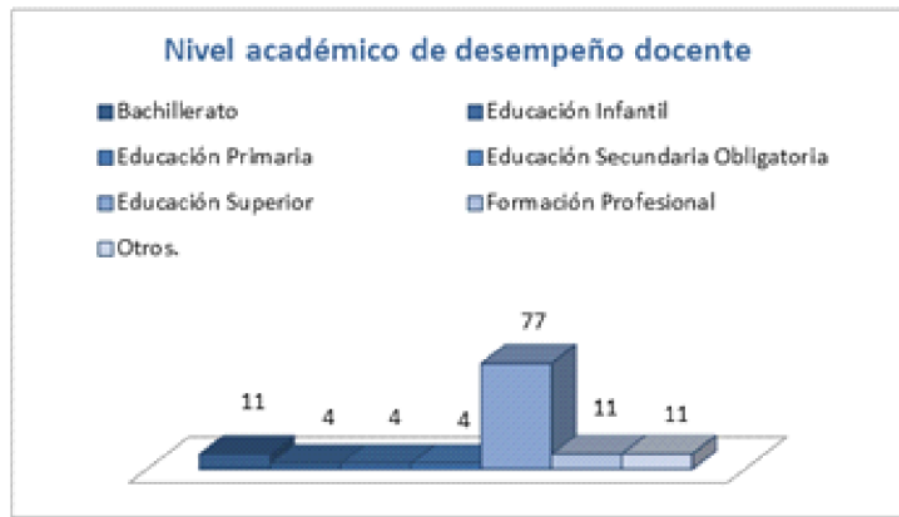

Gráfico 5: Niveles educativos en los que los docentes llevan a cabo su labor.

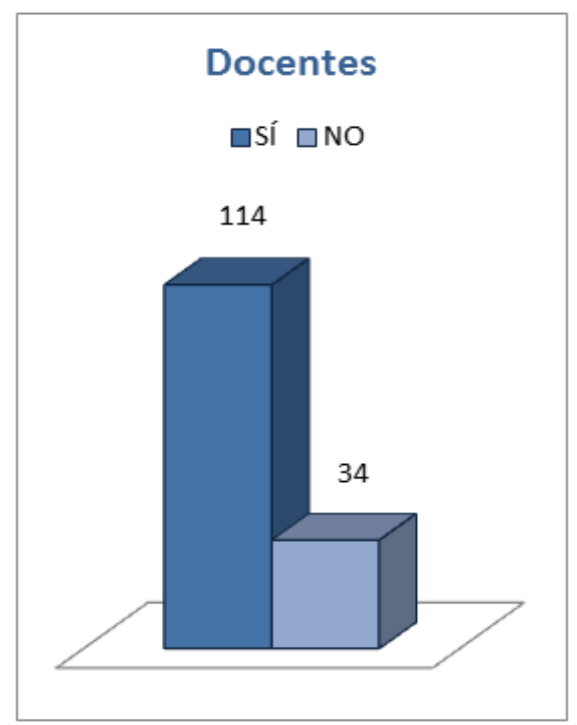

Gráfico 6: De entre los inscritos, destacan los usuarios que desempeñan su trabajo como docentes.

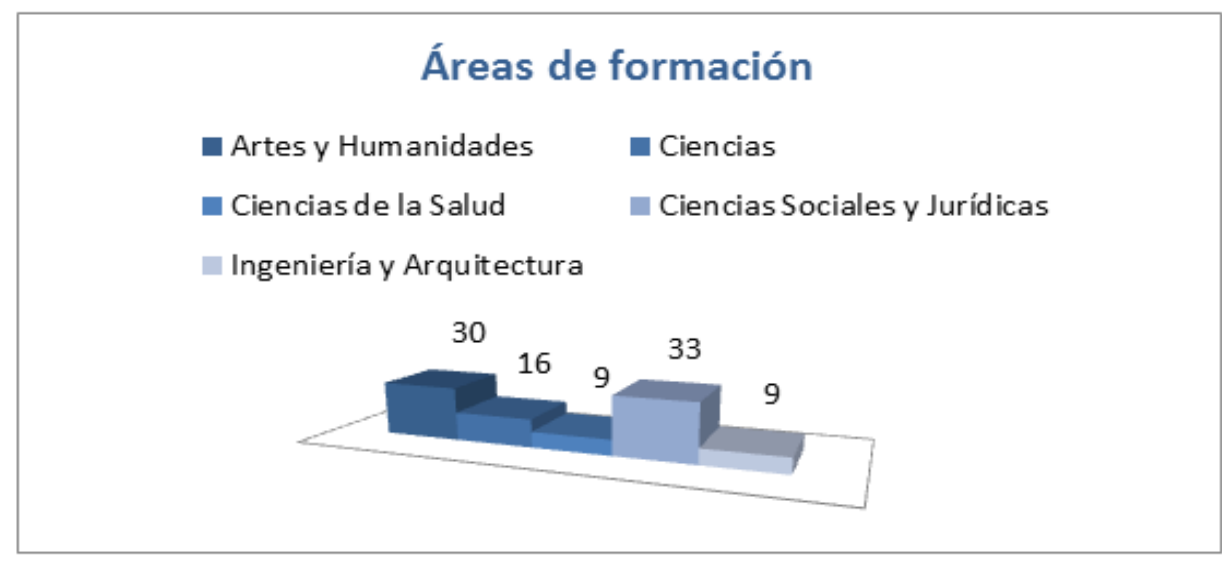

Gráfico 7: Áreas formativas en las que los usuarios imparten formación.

Destacan sobre los demás, los docentes que desarrollan su labor especialmente en las áreas de formación de Artes y Humanidades y Ciencias Sociales y Jurídicas, suponiendo un $65 \%$ del total de ellos, dato que pondría estas, de algún modo, en relación con titulaciones donde aparentemente se podría hacer un menor uso de la tecnología. Entre aquellos estudiantes que no son docentes, son muy variadas los desempeños profesionales, que van desde Ingenieros de Sistemas, Técnicos en Comunicación, Asesores comerciales, hasta Bibliotecarios, Técnicos auxiliares en Drogodependencias, Delineante o estudiantes.

\section{- Evaluación de la información}

Una vez más, en este curso la población femenina supera a la masculina, bajando el intervalo de edad al comprendido entre los 24 y los 44 años de edad, los más elevados, superando juntos más del $71 \%$ del total de los usuarios que respondieron al cuestionario de autoevaluación en los tres niveles de dificultad de esta competencia digital. Aunque cada competencia goza de cierta independencia respecto a otras, el hecho de saber evaluar la calidad de diferentes fuentes de información lleva consigo un grado de experiencia que no suelen poseer los docentes noveles. No es una Los NOOC para la formación en competencias digitales del docente universitario. Una experiencia piloto en una Universidad Nacional de Educación a Distancia (UNED). Lourdes Pérez-Sánchez, María Jordano de la Torre y Ana María Martín-Cuadrado.

Página 18 de 35 
cuestión de formación en competencias digitales sino un factor más relacionado con el grado de madurez del usuario y su formación investigadora al respecto.

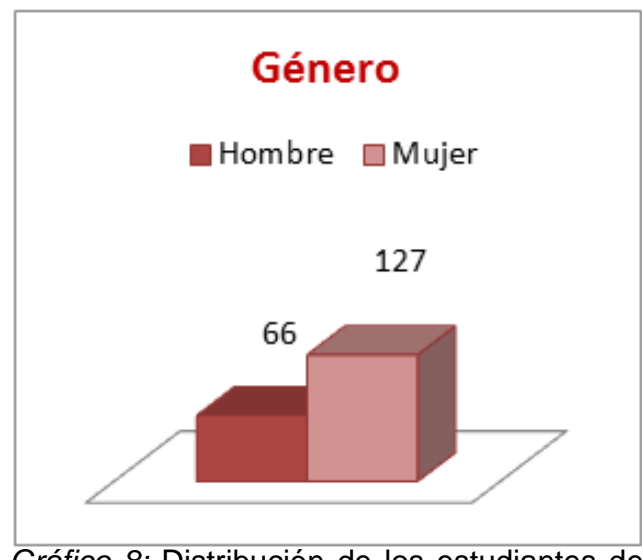

Gráfico 8: Distribución de los estudiantes de la competencia Evaluación, según el Género.

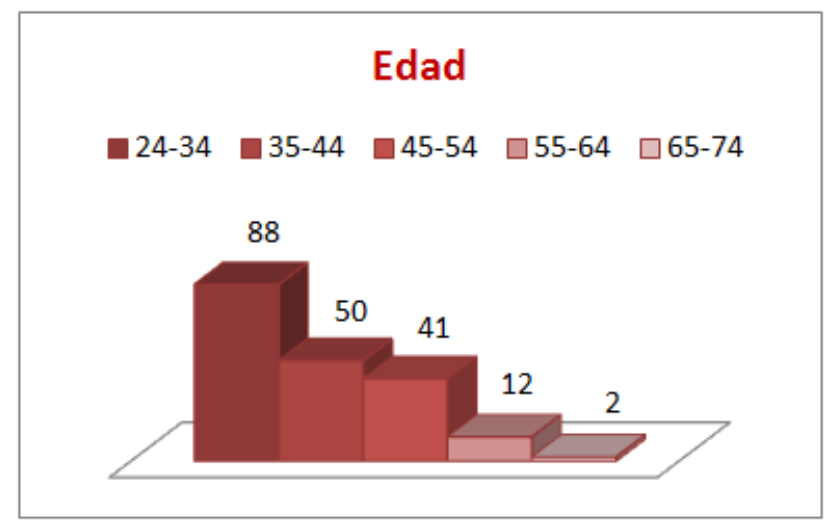

Gráfico 9: Distribución de los estudiantes de la competencia Evaluación, según intervalos de edad.

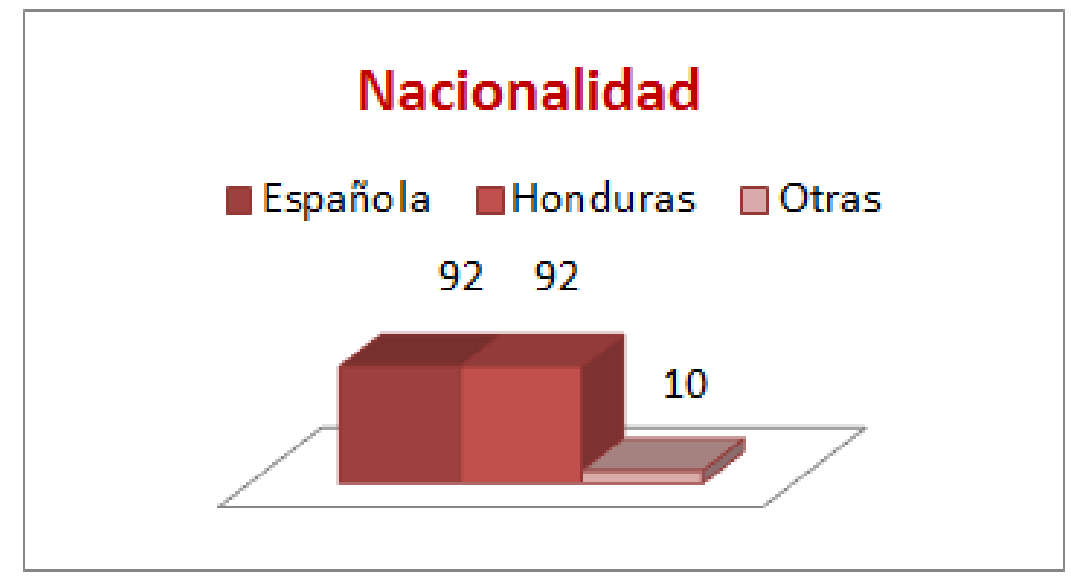

Gráfico 10: Distribución de los estudiantes de la competencia Evaluación, según la Edad según intervalos.

Respeto a la nacionalidad de origen, destacan la hondureña, igualados en número con los españoles.

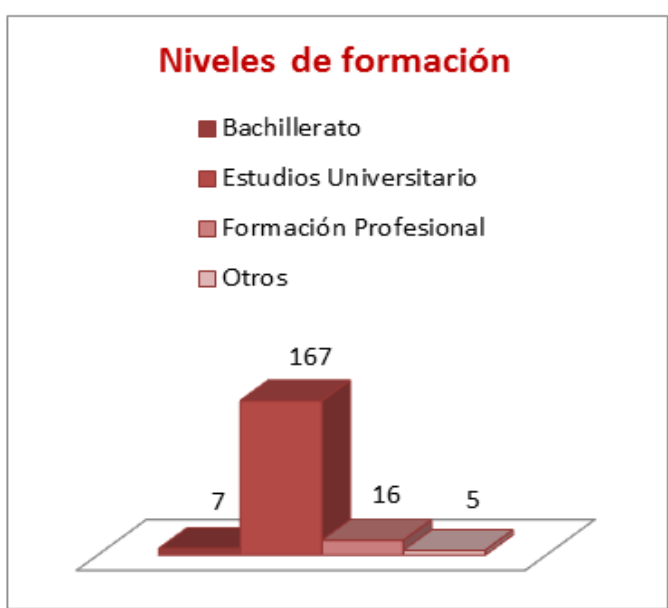

Gráfico 11: Nivel de formación de los usuarios inscritos en el NOOC sobre Evaluación.

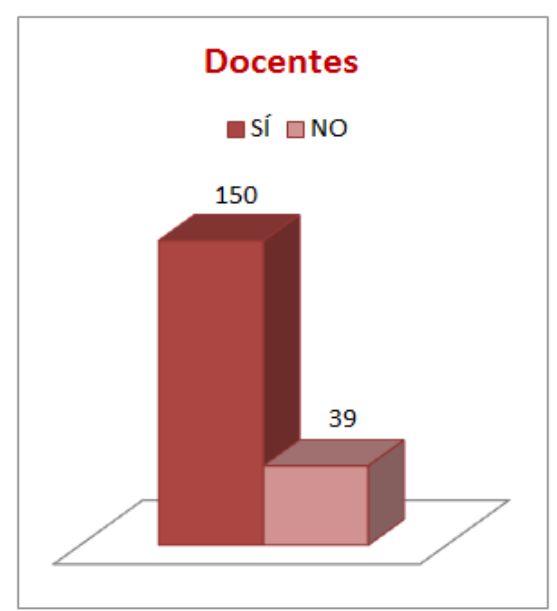

Gráfico 12: Número de docentes entre los usuarios del NOOC sobre Evaluación

Los NOOC para la formación en competencias digitales del docente universitario. Una experiencia piloto en una Universidad Nacional de Educación a Distancia (UNED). Lourdes Pérez-Sánchez, María Jordano de la Torre y Ana María Martín-Cuadrado.

Página 19 de 35 
Al igual que ocurría con la competencia de la navegación, la mayoría son docentes universitarios, y en este caso destaca un alto porcentaje de usuarios relacionados con ciencias sociales y jurídicas.

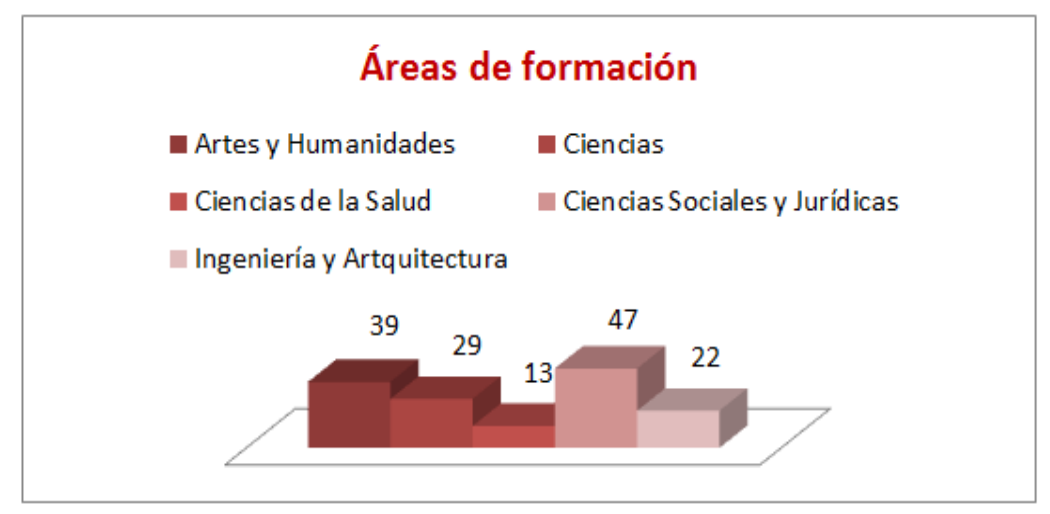

Gráfico 13: Áreas de formación en las que los docentes que cursan los NOOC de Evaluación desempeñan su labor formativa.

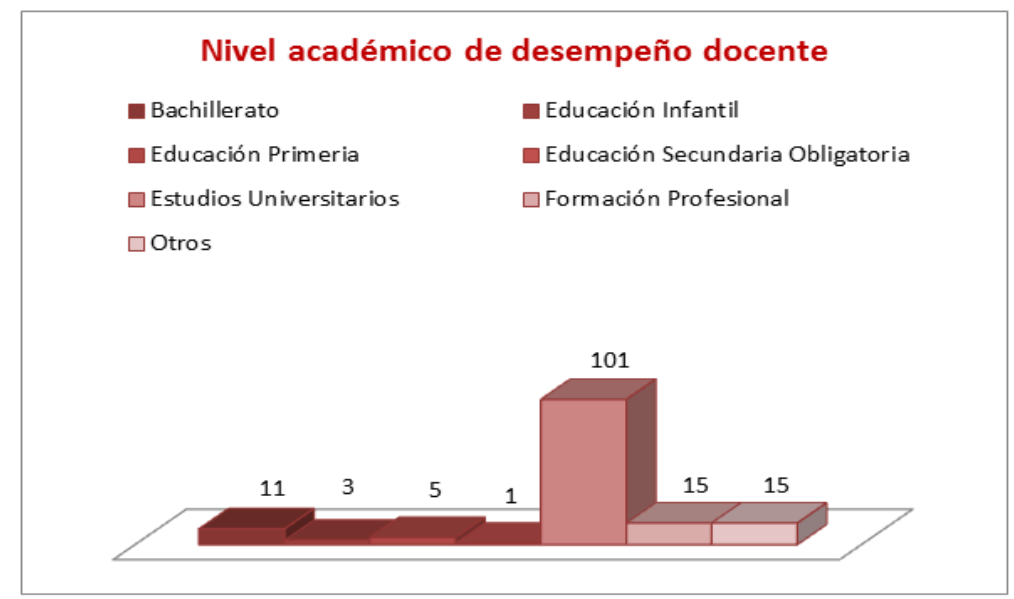

Gráfico 14: Nivel académico en el que los docentes desempeñan su labor

\section{- Almacenamiento y recuperación de la información}

Ésta ha sido el área competencial con mayor número de matriculados, atraídos quizá por ser el área más desconocida de todas, ya que se trabaja desde el principio con diferentes formatos de almacenamiento, que podrían ser desconocidos para algunos usuarios.

Una vez más se repite la misma pauta en cuanto la mayoría femenina registrada en estos cursos

Del mismo modo, destaca el hecho de que los intervalos de edades comprendidas entre los 35 y los 54 años son los más numerosos, suponiendo casi el $74 \%$ de la muestra. En lo que respecta a la nacionalidad sigue siendo la española a predominante, seguida de la hondureña y la argentina. Respecto a la dedicación, en este caso sí que el número de docentes universitarios siguen superando al de otros niveles. El área de formación predominante continúa siendo la de ciencias sociales y jurídicas.

Los NOOC para la formación en competencias digitales del docente universitario. Una experiencia piloto en una Universidad Nacional de Educación a Distancia (UNED). Lourdes Pérez-Sánchez, María Jordano de la Torre y Ana María Martín-Cuadrado.

Página 20 de 35 

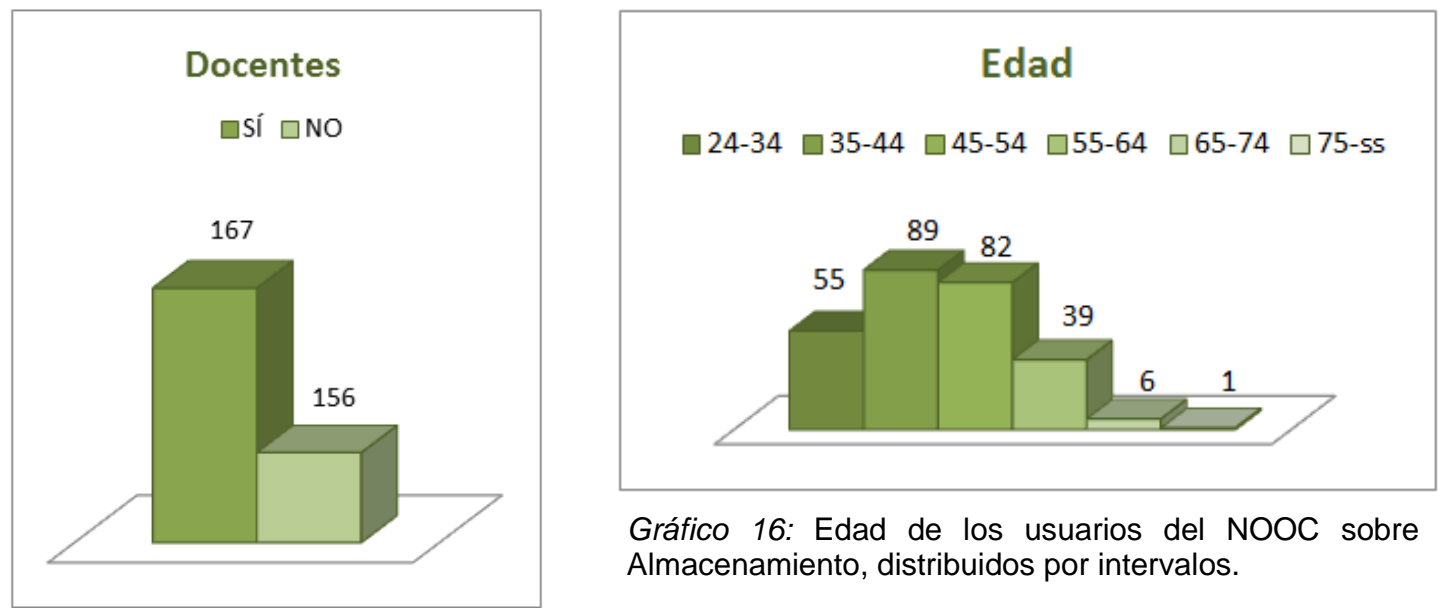

Gráfico 16: Edad de los usuarios del NOOC sobre Almacenamiento, distribuidos por intervalos.

Gráfico 15: Número de docentes entre los usuarios del NOOC sobre Almacenamiento

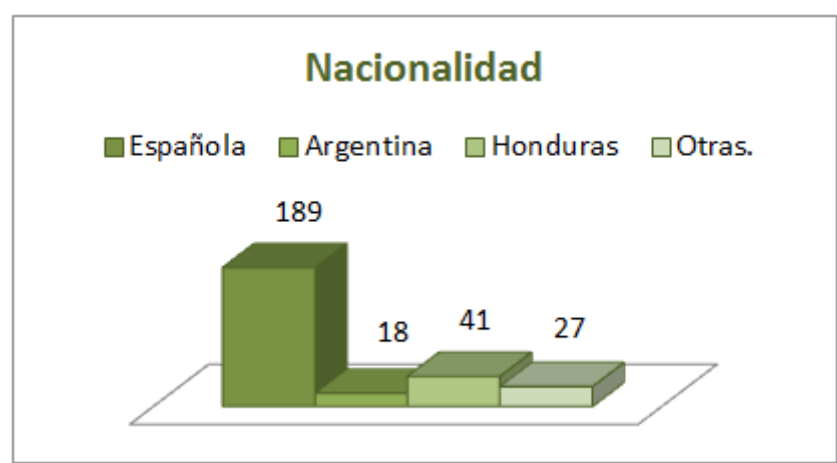

Gráfico 17: Nacionalidad de los estudiantes del NOOC sobre Almacenamiento

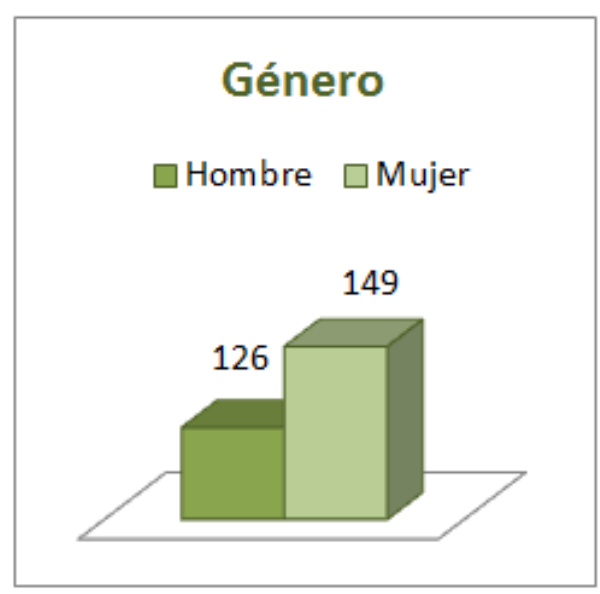

Gráfico 18: Género de los usuarios matriculados en el NOOC sobre Almacenamiento

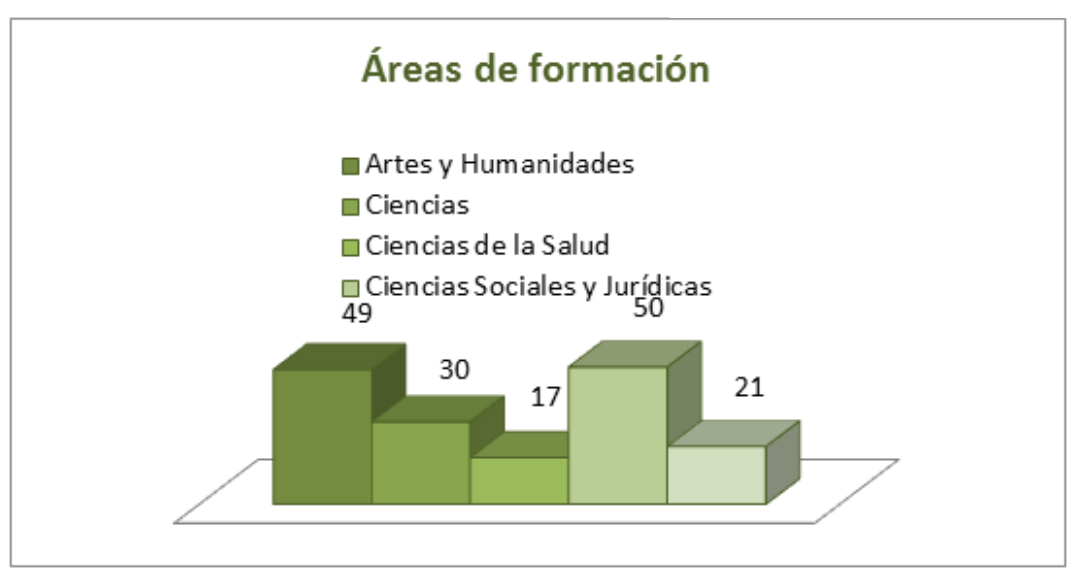

Gráfico 19: Áreas de formación en las que los docentes que cursan los NOOCs de Almacenamiento desempeñan su labor.

Los NOOC para la formación en competencias digitales del docente universitario. Una experiencia piloto en una Universidad Nacional de Educación a Distancia (UNED). Lourdes Pérez-Sánchez, María Jordano de la Torre y Ana María Martín-Cuadrado.

Página 21 de 35 


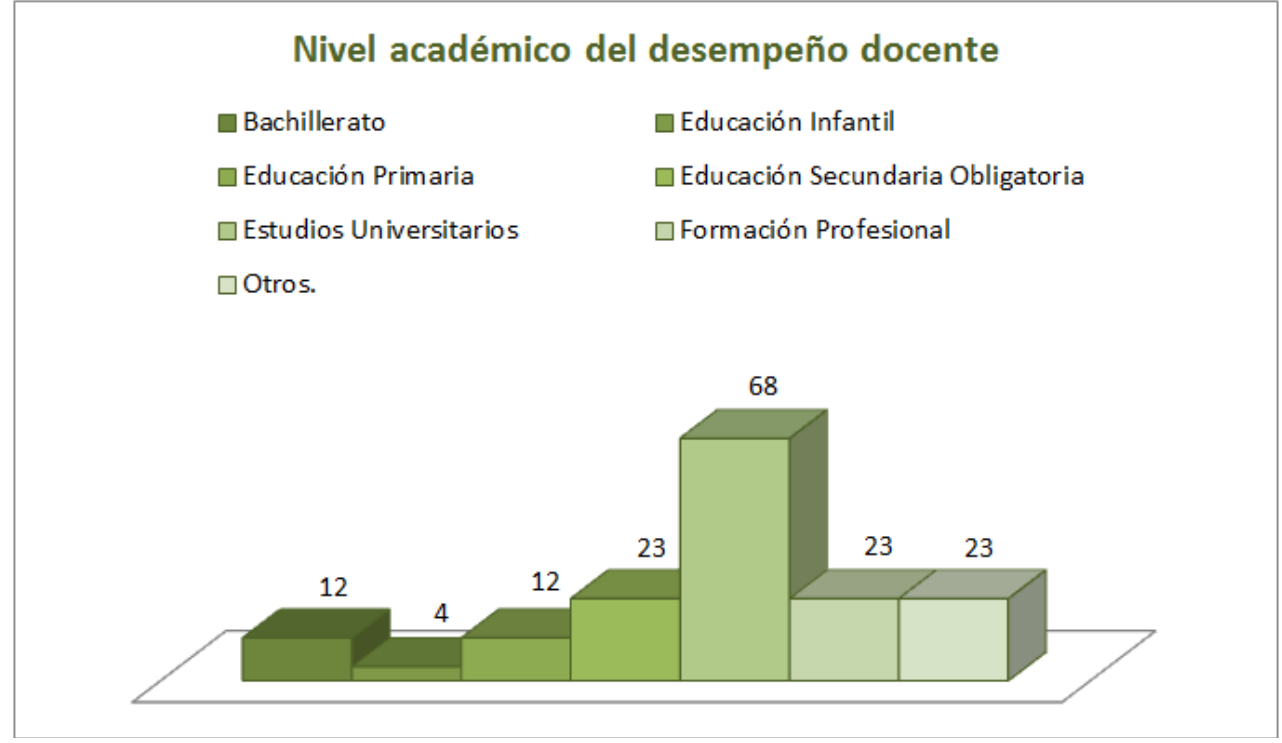

Gráfico 20: Nivel académico en el que los docentes matriculados en los NOOC de Almacenamiento desempeñan su labor.

Como se puede ver a lo largo de las gráficas, los resultados son muy similares, con pequeñas variaciones determinadas por los intereses particulares de los usuarios en cada uno de los cursos. Como se ha mencionado en repetidas ocasiones, estos datos resultan de vital importancia para mejorar versiones futuras de acuerdo con las nuevas actualizaciones de los documentos de la unión europea que han servido para elaborar los contenidos de cada unidad comprendida en los NOOC descritos.

\subsection{Datos de acceso y participación}

Con el fin de conocer mejor el punto de partida y finalización de todos los usuarios inscritos en estos cursos, se han analizado y se muestran a continuación algunos de los datos desprendidos de su estudio. Los gráficos muestran las cifras totales del número de cuestionarios respondidos al inicio y al final de cada curso en cada una de las tres competencias, e incluyendo los tres niveles de dificultad disponibles.

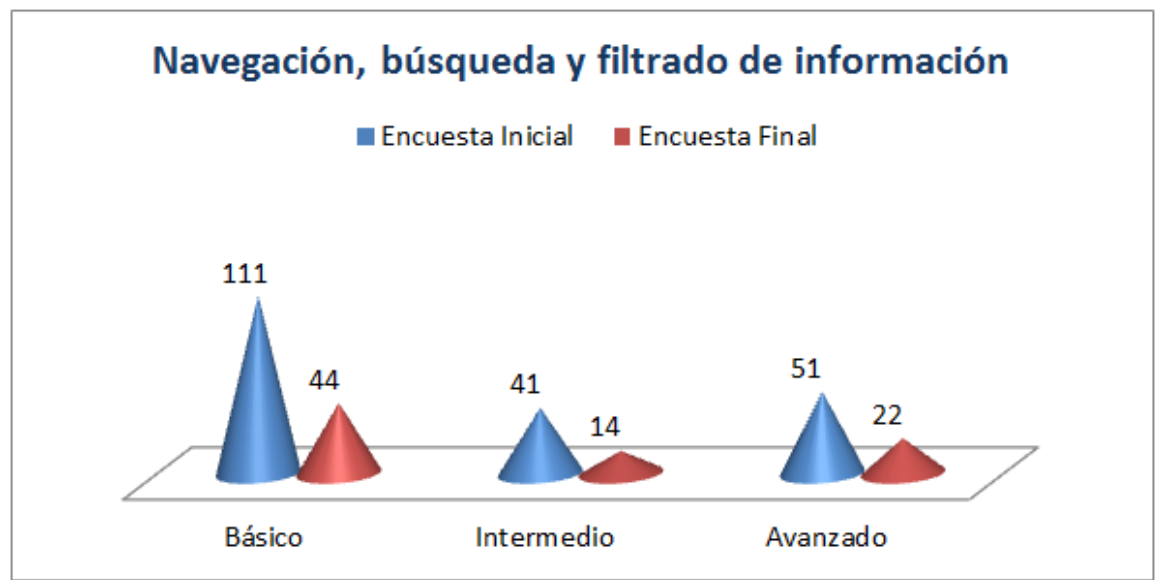

Gráfico 21: Número de usuarios, matriculados en los NOOC de Navegación, que han realizado las Encuestas Inicial y Final.

Los NOOC para la formación en competencias digitales del docente universitario. Una experiencia piloto en una Universidad Nacional de Educación a Distancia (UNED). Lourdes Pérez-Sánchez, María Jordano de la Torre y Ana María Martín-Cuadrado.

Página 22 de 35 


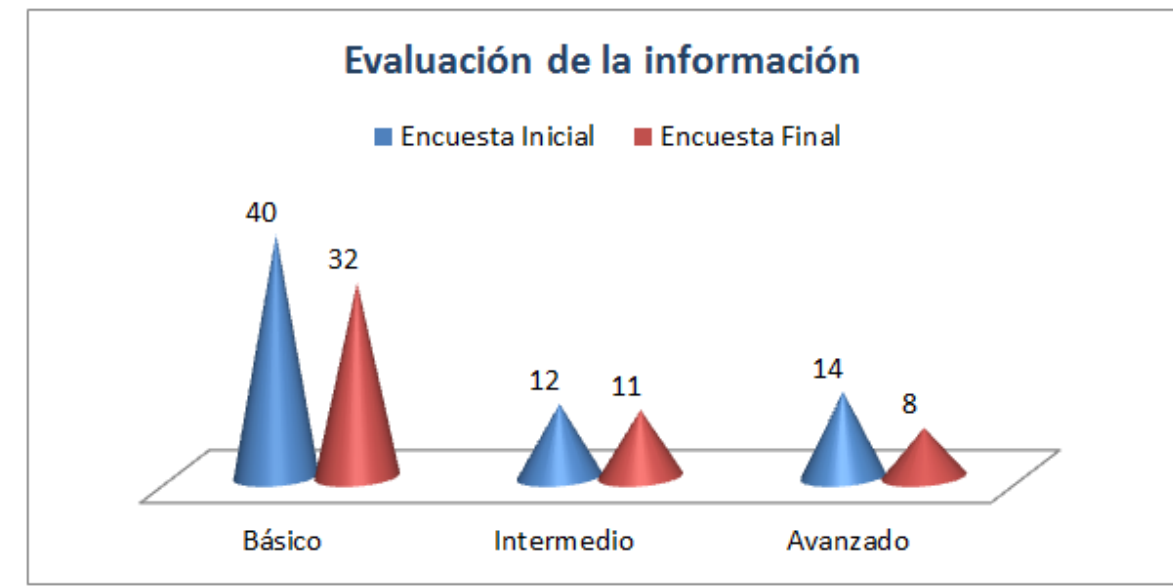

Gráfico 22: Número de usuarios, matriculados en los NOOC de Evaluación, que han realizado las Encuestas Inicial y Final.

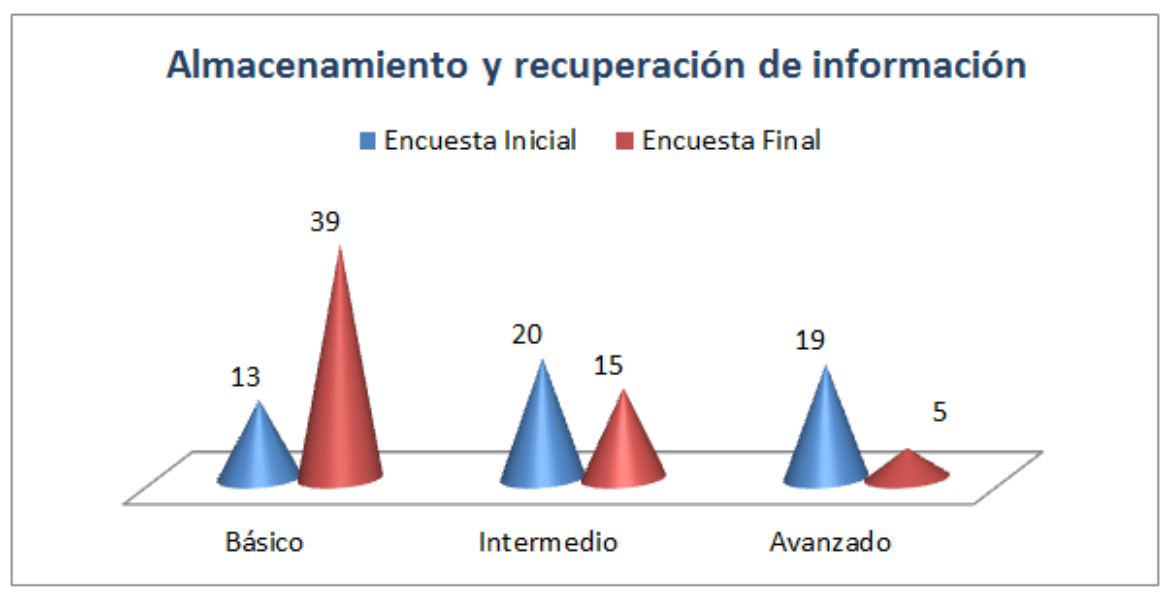

Gráfico 23: Número de usuarios, matriculados en los NOOC de Almacenamiento, que han realizado las Encuestas Inicial y Final.

La participación en la encuesta Inicial ha sido visiblemente superior en la mayoría de los casos, si se compara con la realización de la encuesta final, en todos los cursos y niveles, a excepción del nivel básico del curso de Almacenamiento y recuperación de información.

\section{Conclusiones}

Según se ha podido comprobar en la literatura existente hasta el momento de redactarse este estudio, es la primera experiencia formativa documentada en materia de competencias digitales básicas, en lo que a la docencia universitaria se refiere.

La estructura ofrecida para cada uno de los cursos ofrece instrucciones, foros de discusión y duda, contenidos en diferentes formatos y de carácter multimedia, actividades de diversas características (de ensayo, de reflexión, de participación grupal, de opinión, cuestionarios, prácticas individuales, etc.), y referencias de consulta para ampliar el conocimiento, de carácter complementario (Para Saber +).

Los NOOC para la formación en competencias digitales del docente universitario. Una experiencia piloto en una Universidad Nacional de Educación a Distancia (UNED). Lourdes Pérez-Sánchez, María Jordano de la Torre y Ana María Martín-Cuadrado.

Página 23 de 35 
Se ha puesto de manifiesto la importancia de la realización de una autoevaluación previa al comienzo de los cursos. Esta permitirá al sujeto conocer el nivel de su propio conocimiento y realizar un proceso de reflexión que le facilitará la toma de decisiones sobre qué nivel de dificultad a abordar y en qué contenidos hacer hincapié en su proceso de aprendizaje. Será, así, el propio gestor de su aprendizaje.

Teniendo en cuenta los datos vistos, relativos a las autoevaluaciones podemos extraer una serie de conclusiones comunes a todos los cursos:

- En todos ellos, el número de mujeres es superior al de varones.

- En cuanto a intervalos de edad, destacan los de edades intermedias (35-44 y 45-54 años), principalmente, a excepción del curso de Evaluación de la información donde priman usuarios del primer intervalo de edad (24-34 años).

- Respecto a la procedencia de los registrados destacan la nacionalidad española, por encima de cualquiera, con una diferencia bastante elevada. Además, habría que destacar, la gran diversidad de usuarios del mundo sudamericano, destacando en volumen de usuarios, países como Honduras, Argentina, además de Perú, Venezuela, Chile, Colombia, México, Uruguay o Ecuador entre otros. De forma testimonial, ha habido algún estudiante de Italia, Inglaterra, Portugal o Francia.

- Respecto a la dedicación de los usuarios, a excepción del curso de Almacenamiento y recuperación de la información, el porcentaje de usuarios que desempeñan su tarea profesional en el mundo docente es bastante elevado.

Finalmente, considerando que el número de inscritos no ha sido muy elevado si se compara con otros MOOC ya existentes a nivel general, se debe seguir trabajando en los siguientes aspectos:

- Creación de más videos ad hoc para aquellos apartados donde los usuarios han demostrado tener mayor dificultad.

- Dado que se ha registrado un elevado número de usuarios de nacionalidades fuera de la unión europea, se debería contar con bibliografía de casos contextualizados en países iberoamericanos, como es el caso.

- Proporcionar un mayor grado de interacción y retroalimentación en los foros una vez que los materiales ya han sido creados y se puede dedicar más tiempo a otras tareas que conllevan dedicación adicional.

- Adaptación de las próximas convocatorias a las actualizaciones correspondientes de los documentos editados por la Unión Europea en esta materia.

Tras el análisis y observación de los datos recogidos en este documento, además de la propia observación directa del desarrollo de los NOOC, podemos asegurar que los NOOC se están conformando como una estrategia común para el aprendizaje y puesta al día de los usuarios, que les facilitan el aprendizaje, pudiendo trabajar en pequeñas píldoras de información, concretas y definidas, orientadas a contenidos muy concretos,

Los NOOC para la formación en competencias digitales del docente universitario. Una experiencia piloto en una Universidad Nacional de Educación a Distancia (UNED). Lourdes Pérez-Sánchez, María Jordano de la Torre y Ana María Martín-Cuadrado.

Página 24 de 35 
y que además no les supone mucho tiempo y que permite poder realizarlo en cualquier momento.

Según se desprende de la propuesta del DigComEdu (Redecker, 2017), cinco son las competencias que atañen al entorno educativo del docente. De estas, la primera está directamente relacionada con la temática de nuestro NOOC y la segunda con la próxima propuesta. Es la adaptación de estas, las que deben centrar nuestras futuras investigaciones por mejorar las competencias digitales de docente investigador universitario del s XXI.

Presentación del artículo: 30 de agosto de 2017

Fecha de aprobación: 5 de diciembre de 2017

Fecha de publicación: 22 de diciembre de 2017

Pérez-Sánchez, L., Jordano de la Torre, M. y Martín-Cuadrado, A. M. (2017). Los NOOC para la formación en competencias digitales del docente universitario. Una experiencia piloto en la Universidad Nacional de Educación a distancia (UNED). RED. Revista de Educación a Distancia, 55. Consultado el (dd/mm/aaaa) en http://www.um.es/edad/red/55/perez_et_al.pdf

\section{Financiación}

Esta investigación no ha recibido ninguna subvención específica de los organismos de financiación en los sectores públicos, comerciales o sin fines de lucro.

\section{Referencias}

Adams Becker, S., Cummins, M., Davis, A., Freeman, A., H., \& Giesinger, C., and Ananthanarayanan, V. (2017). HORIZON REPORT 2017 Higher Education. Texas: The New Media Consortium.

Baggaley, J. (2013). MOOC rampant. Distance Education, 34(3), 368-378. Recuperado de: https://doi.org/10.1080/01587919.2013.835768

Banderas Navarro, Nértor. (7 de enero de 2017). TIC, TAC, MOOC, NOOC [XarxaTIC]. Recuperado de: http://www.xarxatic.com/tic-tac-mooc-nooc/

Bárcena Madera, E., Martín Monje, E., y Jordano de la Torre, M. (2016). Innovación metodológica y tecnológica en la enseñanza del inglés para turismo a distancia. Ibérica: Revista de la Asociación Europea de Lenguas para Fines Específicos (AELFE), (31), 39-62.

Cabero Almenara, J. (2015). Visiones educativas sobre los MOOC. RIED: Revista Iberoamericana de Educación a Distancia, 18(2), 39-60. Recuperado de: https://doi.org/10.5944/ried.18.2.13718

Los NOOC para la formación en competencias digitales del docente universitario. Una experiencia piloto en una Universidad Nacional de Educación a Distancia (UNED). Lourdes Pérez-Sánchez, María Jordano de la Torre y Ana María Martín-Cuadrado.

Página 25 de 35 
Campal, F. (2017). MOOC, NOOC, SPOC, PODCAST, Webinars, Charlas TED y otros recursos para aprender por aprender. Recuperado de: http://www.biblogtecarios.es/felicampal/mooc-nooc-spoc-recursos-para-aprenderpor-aprender/

Carretero, S., Vuorikari, R., \& Punie, Y. (2017). The Digital Competence Framework for Citizens With eight proficiency levels and examples of use. Luxemburgo: Publications Office of the European Union. Recuperado de: https://doi.org/10.2760/38842

Clark, D. (2013). MOOCs: taxonomy of 8 types of MOOC. Recuperado de: http://donaldclarkplanb.blogspot.com.es/search?q=MOOCs:+taxonomy

Coakley, D., Garvey, R., \& O'Neill, Í. (2016). Micro-learning-Adopting Digital Pedagogies to Facilitate Technology-Enhanced Teaching and Learning for CPD. En Empowering 21st Century Learners Through Holistic and Enterprising Learning (pp. 272-275). Malaysia: Springer Singapore. Recuperado de: https://doi.org/10.1007/978-981-10-4241-6_24

Conde, M. Á., García-Peñalvo, F. J., Rodríguez-Conde, M. J., Alier, M., Casany, M. J., \& Piguillem, J. (2014). An evolving Learning Management System for new educational environments using 2.0 tools. Interactive Learning Environments, 22(2), 188-204. doi:10.1080/10494820.2012.745433

Council of Europe. (2001). Common European Framework of Reference for Languages. Estrasburgo: Cambridge University Press.

Czerniewicz, L., Deacon, A., Glover, M., \& Walji, S. (2017). MOOC-making and open educational practices. Journal Of Computing In Higher Education, 29(1), 81-97. Recuperado de: https://doi.org/10.1007/s12528-016-9128-7

De Vincenzi, A. (2012). La formación pedagógica del profesor universitario. Un desafío para la reflexión y revisión de la práctica docente en el nivel superior. Aula: revista de enseñanza e investigación educativa, 18(18), 111-122. Recuperado de: https://doi.org/http://revistas.usal.es/index.php/0214-3402/article/view/8875

Farrán, M.A. y Pérez, M. (2017). Diseño de un MOOC: química orgánica básica para el curso de bioquímica del grado de química. En A.M. Martín-Cuadrado, E. Juan y N. Carriedo (coords.). Actas VIII Jornadas de Redes de Investigación en Innovación Docente (pp.43-45). Madrid, España: UNED.

Fernández, J. V., \& Webster, S. (2014). From OCW to MOOC: Deployment of OERs in a Massive Open Online Course. The Experience of Universidad Carlos III de Madrid (UC3M). Open Praxis, 6(2), 145-158. Recuperado de: https://doi.org/10.5944/openpraxis.6.2.115

Ferrari, A. (2013). DIGCOM: A Framework for Developing and Understanding Digital Competence in Europe. (N. . Punie, Yves; Brecko, Ed.), Joint Research Centre, European Comission. Luxenburgo. Recuperado de: https://doi.org/10.2788/52966

Los NOOC para la formación en competencias digitales del docente universitario. Una experiencia piloto en una Universidad Nacional de Educación a Distancia (UNED). Lourdes Pérez-Sánchez, María Jordano de la Torre y Ana María Martín-Cuadrado.

Página 26 de 35 
Fidalgo-Blanco, Á., Sein-Echaluce, M. L., \& García-Peñalvo, F. J. (2016). From massive access to cooperation: Lessons learned and proven results of a hybrid $\mathrm{xMOOC/cMOOC}$ pedagogical approach to MOOCs. International Journal of Educational Technology in Higher Education (ETHE), 13, 24. doi:10.1186/s41239-016-0024-z

García Aretio, L. (2015). MOOC: ¿tsunami, revolución o moda pasajera? RIED: Revista Iberoamericana de Educación a Distancia, 18(1), 9-21. Recuperado de: https://doi.org/http://dx.doi.org/10.5944/ried.18.1.13812

Gea, M. (2016). Informe MOOC y criterios de calidad. Versión 1.0. Toledo.

Gisbert, M., Espuny, C., y González, J. (2011). Incotic. Una herramienta para la @utoevaluación de la competencia digital en la universidad. Profesorado. Revista de currículum y formación del profesorado, 15, 75-90.

Gisbert, M., Martínez, J. G., y Mon, F. M. E. (2016). Competencia digital y competencia digital docente: una panorámica sobre el estado de la cuestión. Revista Interuniversitaria de Investigación en Tecnología Educativa, 0 (Junio), 74-83.

Glass, C. R., Shiokawa-Baklan, M. S., \& Saltarelli, A. J. (2016). Who Takes MOOCs? New Directions for Institutional Research, 2015(167), 41-55. Recuperado de: https://doi.org/10.1002/ir.20153

Gómez-Ortega, J. (2016). UNIVERSITIC 2016 Análisis de las TIC en las Universidades Españolas. Madrid.

Hanson-Smith, E. (2004). Professional Development: The Electronic Village Online of the TESOL CALL Interest Section. TESL-EJ: Teaching English as a Second or Foreign Language, 8(2). Recuperado de: https://doi.org/http://teslej.org/ej30/int.html

Ikanos. (2015). Test de autodiagnóstico de competencias digitales. Recuperado de: http://ikanos.encuesta.euskadi.net/index.php/566697/lang-es. Fecha de consulta: 22 de julio de 2017

INTEF. (2013a). Marco Común de COMPETENCIA DIGITAL DOCENTE. Madrid.

INTEF. (2013b). Plan de Cultura Digital en la Escuela | Blog de INTEF. Recuperado de: http://blog.educalab.es/intef/2013/04/16/plan-de-cultura-digital-en-la-escuela/

INTEF. (2013c). Plan de Cultura Digital en la Escuela | Blog de INTEF. Recuperado 25 de agosto de 2017, a partir de http://blog.educalab.es/intef/2013/04/16/plan-decultura-digital-en-la-escuela/

INTEF. (2017). Enseñar y evaluar la competencia digital (4 $4^{a}$ edición) | MOOC INTEF. Recuperado de: http://mooc.educalab.es/courses/course-v1:MOOCINTEF+INTEF175+2017_ED4/about

Jordano, M., Martín-Cuadrado, A.M. y Pérez-Sánchez, L. (2017). La formación de competencias digitales básicas, un paso más para el desarrollo profesional del

Los NOOC para la formación en competencias digitales del docente universitario. Una experiencia piloto en una Universidad Nacional de Educación a Distancia (UNED). Lourdes Pérez-Sánchez, María Jordano de la Torre y Ana María Martín-Cuadrado.

Página 27 de 35 
docente universitario. [Programa Audiovisual]. Madrid, España: CanalUNED. Recuperado de: https://canal.uned.es/mmobj/index/id/57365

Jordano de la Torre, María. (2009). La enseñanza de la ELAO en el contexto de la educación a distancia en las puertas del EEES: del texto impreso a la web 2.0, en Investigar desde un contexto educativo innovador, Roig Vila, R. (Ed) Editorial Marfil, Alicante (pag. 235-250)

Junta de Andalucía (2016). Herramienta de autodiagnóstico en competencias digitales. Portal de Formación. Andalucía es digital. Sevilla, España. Recuperado de: http://www.digcomp.andaluciaesdigital.es/

Junta de Andalucía (20 de abril de 2017). Del MOOC al NOOC, un nuevo modelo de formación especializada, online y exprés. [Andalucía es digital] Recuperado de: http://www.blog.andaluciaesdigital.es/nooc-la-evolucion-del-mooc/

Kopp, M., y Ebner, M. (2017). La certificación de los MOOC. Ventajas, desafíos y experiencias prácticas. Revista Española de Pedagogía, 75(1), 83-100. Recuperado de: https://doi.org/10.22550/REP75-1-2017-05

Lázaro, J. L., y Gisbert, M. (2015). Elaboración de una rúbrica para evaluar la competencia digital del docente. UT. Revista de Ciències de l'Educació, 1, 30-47.

Lirsa, Cécile Dejoux, Charrière-Grillon, V. (2016). How Digital Technologies are revolutionising the training function in companies: an exploratory study of a population of managers. Revue de Gestion des Ressources Humaines, 102, $42-$ 58.

Manzano Soto, N., Martín Cuadrado, A.M., Sánchez García, M., Rísquez, A., y Suárez Ortega, M. (2012). El rol del mentor en un proceso de mentoría universitaria. Educación XXI : revista de la Facultad de Educación, 15(2), 93-1118. Recuperado de: https://doi.org/10.5944/educxx1

Martín-Cuadrado, A.M., Cerrada, C., Jordano, M. y Cons, D. (2017).Developing of a Catalogue of Digital Resources for Competence/Skills Training (chapter.3). En Janerik Lundquist (Ed.) Good Practice Guide.The Use of Digital Resources in University Programmes Digital Literacy as a Way to Improve Students' Employability. Case Studies from the COLISEE Project (pp. 58-81). LiU-Tryck, Universitetet i Linköping,Sweden. Recuperado de: https://old.liu.se/colisee/projectdocumentation/1.721250/TheUseofDigitalResourcesinUniversityProgrammes. Guid etoGoodPractice

Moral Pérez, M. E. del, y Villalustre Martínez, L. (2015). MOOC: ecosistemas digitales para la construcción de PLE en la educación superior. RIED: Revista Iberoamericana de Educación a Distancia, 18(2), 87-107. Recuperado de: https://doi.org/http://dx.doi.org/10.5944/ried.18.2.13353

Pardos, Z. A., \& Schneider, E. (2013). Welcome to the MOOCcspace: a proposed theory and taxonomy for massive open online courses. En The 16th International

Los NOOC para la formación en competencias digitales del docente universitario. Una experiencia piloto en una Universidad Nacional de Educación a Distancia (UNED). Lourdes Pérez-Sánchez, María Jordano de la Torre y Ana María Martín-Cuadrado.

Página 28 de 35 
Conference on Artificial Intelligence in Education (Volume I) (pp. 2-9). Tennessee, USA.

Pelayo, A., Rodríguez A., de Castro, C., Marcos,T., Regueiro M.T., Pérez,S., Gómez de Liaño, M. y Amérigo, F. (2017). Cursos MOOC para facilitar el acceso a criterios jurídicos básicos. Claves jurídicas para la gestión de la diversidad. En A.M. Martín-Cuadrado, E. Juan y N. Carriedo (coords.). Actas VIII Jornadas de Redes de Investigación en Innovación Docente (pp.43-45). Madrid, España: UNED. ISBN:978-84-697-4184-9

Pérez-Escoda, A. \& González Fernández-Villacencio, N. (2016). Digital Competence in Use: From Digcomp 1 to Digcomp 2. En TEEM '16 Proceedings of the Fourth International Conference on Technological Ecosystems for Enhancing Multiculturality (pp. 619-624). New York: ACM. Recuperado de: https://doi.org/10.1145/3012430.3012583

Píriz Durán, S. (2015). Análisis de las TIC en las Universidades Españolas. Madrid: CRU Universidades Españolas.

Pozos, K.V. (2009). La competencia digital del profesorado universitario para la sociedad del conocimiento. Un modelo para la integración de la competencia digital en el desarrollo profesional docente. En $V$ Congreso de formación para el trabajo. Granada, 24-27 de junio del 2009. Recuperado de: https://www.academia.edu/485126/La_Competencia_Digital_del_Profesorado_Uni versitario_para_la_Sociedad_del_Conocimiento_Un_Modelo_para_la_Integraci\% C3\%B3n_de_la_Competencia_Digital_en_el_Desarrollo_Profesional_Docente

Poy, R., y Gonzales-Aguilar, A. (2014). Factores de éxito de los MOOC: algunas consideraciones críticas. RISTI (Revista lbérica de Sistemas e Tecnologias de Informacao), 105-118. Recuperado de: https://doi.org/10.4304/risti.e1.105-118

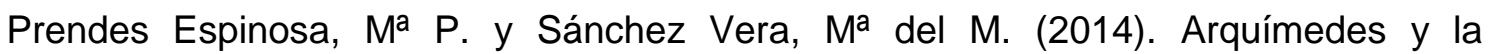
tecnología educativa: un análisis crítico en torno a los MOOC. Revista Interuniversitaria de Formación del Profesorado, 79 (28.1), 29-49. Recuperado de: http://www.aufop.com/aufop/revistas/arta/impresa/183/1875

Radom, R., \& Gammons, R. W. (2014). Teaching Information Evaluation with the Five Ws. Reference \% User Services Quaterly, 53(4), 334-47.

Redecker, C. (2017). Resumen de la propuesta para DigCompEdu (No. Marzo 1917). Luxemburgo.

Rodríguez Gómez, G., Ibarra Sáiz, M. S., y García Jiménez, E. (2013). Autoevaluación, evaluación entre iguales y coevaluación: conceptualización y práctica en las universidades españolas. Revista de investigación en educación, 2(11), 198-210.

Sangrà, A., González-Sanmamed, M., y Anderson, T. (2015). Metaanálisis de la investigación sobre MOOC en el período 2013-2014. Educación XXI: revista de la

Los NOOC para la formación en competencias digitales del docente universitario. Una experiencia piloto en una Universidad Nacional de Educación a Distancia (UNED). Lourdes Pérez-Sánchez, María Jordano de la Torre y Ana María Martín-Cuadrado.

Página 29 de 35 
Facultad de Educación, 18(2). Recuperado de: https://doi.org/http://dx.doi.org/10.5944/educxx1.13463

Santamaría, M. (2014a). MOOCS y SPOCS: sus posibilidades para la formación del profesorado. Revista Hamut'ay 1 (1), enero-junio 2014, 6-17.

Santamaría, M. (2014b). El papel de las instituciones universitarias en la promoción de la innovación docente. Las Redes de Investigación en Innovación Docente de la UNED (2007-2013). En A. Sánchez-Elvira y M. Santamaría Lancho (coords.) Actas VI Jornadas de Redes de Investigación en Innovación Docente (pp. 175184). Madrid, España: UNED. Recuperado de: http://congresos.uned.es/w5400/archivos_publicos/qweb_paginas/5267/vilibrored esuned.pdf

Sein-Echaluce, M. L., Fidalgo-Blanco, Á., \& Alves, G. (2017). Technology Behaviors in Education Innovation. Computers in Human Behavior, 72, 596-598. doi:10.1016/j.chb.2016.11.049

Schoonbaert, D., \& Rosenberg, V. (2010). Personal Bibliographic Systems (PBS). En Encyclopedia of Library and Information Sciences (pp. 4127-4136). Taylor \& Francis.

Sosa Díaz, M. J., Díaz Flores, S. R., \& López Andrada, C. (2014). Comunidad de aprendizaje y participación social en un curso MOOC. IJERI: International journal of Educational Research and Innovation, 1-13.

Unesco. (2008). Estándares Unesco De Competencia En Tic Para Docentes. Organización de las naciones unidas para la educación la ciencia y la cultura (Unesco), 1-28.

Vázquez Cano, E., y López Meneses, E. (2015). La filosofía educativa de los MOOC y la educación universitaria. RIED: Revista Iberoamericana de Educación a Distancia, 18(2), 25-37.

Vuorikari, R., Punie, Y., Carretero Gomez S., y Van den Brande, G. (2016). DigComp 2.0: The Digital Competence Framework for Citizens. Update Phase 1: The Conceptual Reference Model. Luxembourg Publication Office of the European Union. EUR 27948 EN. doi:10.2791/11517 


\section{ANEXOS}

\section{Anexo I: Encuesta Inicial.}

Sexo: Hombre/Mujer.

Año de nacimiento.

País de residencia.

Nivel de estudios.

Situación laboral:

Estudiante.

Trabajador por cuenta ajena.

Trabajador autónomo.

En situación de desempleo.

Jubilación/pensionista.

Otro.

Sobre su experiencia en cursos masivos on-line abierto (COMA/MOOC):

He realizado otros cursos en UNED COMA.

He realizado otros cursos $\mathrm{MOOC}$ en otras plataformas.

Nunca he realizado cursos de este tipo con anterioridad.

En qué otras plataformas ha cursado MOOCs:

MiriadaX.

Coursera.

Udacity.

edX

p2p University.

Motivos por los que realiza este curso:

Me interesa la temática del curso.

La metodología del curso me resulta cómoda.

El curso es útil para conocer mejor la UNED.

El curso es útil para mi desarrollo profesional.

El prestigio de la UNED me anima a realizar un curso en esta institución.

Me interesa tener acceso a contenidos concretos del curso.

Me interesa interactuar con otros estudiantes con quienes comparto intereses.

Me interesa tener acceso a profesorado experto en la temática.

En cuanto a sus expectativas al realizar este curso:

Mi intención es consultar los materiales pero no espero finalizar el curso.

Espero realizar algunas de las actividades pero no creo que complete todo el

curso.

$$
\text { Espero completar el curso completo. }
$$

Los NOOC para la formación en competencias digitales del docente universitario. Una experiencia piloto en una Universidad Nacional de Educación a Distancia (UNED). Lourdes Pérez-Sánchez, María Jordano de la Torre y Ana María Martín-Cuadrado.

Página 31 de 35 


\section{Anexo II: Encuesta Final.}

¿Has finalizado?: sí / NO.

Sexo: Hombre/Mujer.

Año de nacimiento.

País de residencia.

Nivel de estudios.

Valore de 0 a 10 las siguientes opciones:

El curso se ha ajustado a mis expectativas previas.

Los contenidos del curso me han parecido adecuados y suficientes.

La metodología del curso me ha resultado motivadora y apropiada.

La duración del curso me ha parecido adecuada.

El curso está bien organizado / estructurado.

La plataforma virtual ha funcionado correctamente.

He utilizado los siguientes elementos del curso:

Documentos escritos.

Mapa conceptual.

Foro.

Los siguientes elementos del curso son útiles para el aprendizaje y el progreso en el curso:

Documentos escritos.

Mapa conceptual.

Foro.

Valore de 0 a 10 las siguientes opciones:

Recomendaría este curso a otras personas interesadas en la temática. posibilidades.

La realización de este curso me ha permitido conocer mejor la UNED y sus

Me gustaría realizar más cursos de este tipo (COMA /MOOC) en la UNED.

Tras realizar este curso, me gustaría realizar otro tipo de cursos en la UNED (estudios oficiales, títulos propios, etc.).

Los NOOC para la formación en competencias digitales del docente universitario. Una experiencia piloto en una Universidad Nacional de Educación a Distancia (UNED). Lourdes Pérez-Sánchez, María Jordano de la Torre y Ana María Martín-Cuadrado.

Página 32 de 35 


\section{Anexo III}

Los cuestionarios de Autoevaluación, preparados para cada curso, recogen los siguientes indicadores:

\section{Indicadores Nivel BÁSICO para Navegación, búsqueda y filtrado de información.}

Conceptos básicos de navegación (navegador, motor de búsqueda, búsqueda, metabuscador, directorio, indexación, descriptor, palabra clave, URL, archivos, directorios, formato, www, hipervínculo)

Diversos navegadores, sus características, así como la conveniencia de utilizar unos $u$ otros según el caso

Instalación de un navegador en el ordenador

Estrategias básicas de búsqueda de información (uso del navegador, uso de dirección web de una página)

Diferentes tipos de archivos en diversos formatos: imagen, texto, pdf, video, audio. (conocimiento y manejo)

Indicadores Nivel INTERMEDIO para Navegación, búsqueda y filtrado de información.

Estrategias de búsqueda avanzada

Espacios de búsquedas especializados (bibliotecas, catálogos, centros de documentación, bases de datos, literatura gris, citas bibliográficas, diccionarios, traductores)

Operadores booleanos para búsquedas avanzadas.

Buscadores / Base de datos Académicos (entre otros, ERIC, Teseo, Redalyc, Dialnet, Scielo, Google Scholar - Académico, ...)

Buscadores / Base de datos de Imágenes (entre otros, Behold, Creativa Commons Search, Foter, Google Imágenes, Pixsy, TinEye, Veezzle ...)

Espacios de búsqueda especializada en Google (Google Books, Videos Youtube, Maps, Calendar, Traductor, etc.)

Buscar y gestionar información de interés. (Google Alertas.)

Indicadores Nivel AVANZADO para Navegación, búsqueda y filtrado de información.

Conceptos básicos: marcadores sociales, redes sociales y blog.

Conocimiento de marcadores sociales como Pinterest, Stumbreupon.com, delicious.com, digg.como, scoop.it, etc.

Gestionar y compartir la información a través de los marcadores

Redes sociales Educativas (Docsity, educaNetwork, Edmodo, Gnoss Educa, Diipo,...)

Redes sociales NO Educativas (Facebook y Twitter).

Estrategias para gestionar y compartir información a través de una Red Social.

Elaborar y compartir información de forma colaborativa. Google Drive.

Los NOOC para la formación en competencias digitales del docente universitario. Una experiencia piloto en una Universidad Nacional de Educación a Distancia (UNED). Lourdes Pérez-Sánchez, María Jordano de la Torre y Ana María Martín-Cuadrado.

Página 33 de 35 


\section{Indicadores Nivel BÁSICO para Evaluación de la información.}

No toda la información que aparece en la red es fiable

Uso Wikipedia y la cito como fuente de conocimiento

Uso las redes sociales como fuente de información

Se distinguir entre diferentes tipos de fuentes (textos divulgativos, didácticos, científicos, etc.) y se dónde encontrarlos

Siempre cito la fuente al tomar ideas de fuentes externas

\section{Indicadores Nivel INTERMEDIO para Evaluación de la información.}

Utilizo Google para buscar información académica

Uso Google Académico

Criterios de calidad de fuentes web

Criterios de calidad de fuentes escritas

Involucro a los estudiantes en el uso ético de la información

\section{Indicadores Nivel AVANZADO para Evaluación de la información.}

Utilizo bases de datos como forma de búsqueda de información

Sé distinguir bases de datos atendiendo a indicios de calidad

Uso metabuscadores que me ayudan a ahorrar tiempo

Sé cómo detectar plagios

Conozco herramientas para detectar plagios

Indicadores Nivel BÁSICO para Almacenamiento y recuperación de la información.

Conozco cómo almacenar y recuperar información en formato texto, audio y video desde diferentes dispositivos.

Conozco cómo almacenar y recuperar información de Internet (referente a páginas web y documentos audiovisuales)

Utilizo la nube para guardar y recuperar información en diferentes formatos

Conozco la existencia de gestores bibliográficos para gestionar referencias bibliográficas

Conozco la importancia de realizar copias de seguridad

Indicadores Nivel INTERMEDIO para Almacenamiento y recuperación de la información.

Capacidad para almacenar cualquier tipo de formato y facilidad para localizarlo posteriormente Conocimiento de aplicaciones específicas para almacenar y gestionar cualquier tipo de formato de manera ordenada (gestores de notas, bibliográficos, etc.)

Los NOOC para la formación en competencias digitales del docente universitario. Una experiencia piloto en una Universidad Nacional de Educación a Distancia (UNED). Lourdes Pérez-Sánchez, María Jordano de la Torre y Ana María Martín-Cuadrado.

Página 34 de 35 
Técnicas para localizar información ya almacenada desde diferentes dispositivos.

Uso de complementos para el navegador y dispositivos móviles que faciliten el almacenamiento de información (Clipper y otros)

Inclusión y gestión de referencias bibliográficas en gestores bibliográficos

Exportación directa e indirecta a gestores bibliográficos desde diferentes bases de datos y proveedores de contenido electrónico

Gestión de plataformas de libros electrónicos

Indicadores Nivel AVANZADO para Almacenamiento y recuperación de la información.

Uso de gestores de notas bibliográficas para planificar y gestionar mi docencia

Trabajo colaborativo mediante gestores de notas electrónicas

Elaborar y compartir listados bibliográficos de manera grupal

Utilización de gestores bibliográficos para redactar materiales y elaborar bibliografías para los alumnos

Acceder a redes académicas para mantenerme actualizad@en mis temas de interés (Research Gate, Google Citations y Academia)

Gestión de académicas sociales para almacenar y difundir mis publicaciones (Research Gate, Google Citations y Academia)

Privacidad y seguridad en la red

Los NOOC para la formación en competencias digitales del docente universitario. Una experiencia piloto en una Universidad Nacional de Educación a Distancia (UNED). Lourdes Pérez-Sánchez, María Jordano de la Torre y Ana María Martín-Cuadrado.

Página 35 de 35 